\title{
Review \\ Screening of Cognitive Changes in Adults with Intellectual Disabilities: A Systematic Review
}

\author{
Andreia F. Paiva ${ }^{1}$, Adam Nolan ${ }^{2}$, Charlotte Thumser ${ }^{3}$ and Flávia H. Santos ${ }^{4 *}$ \\ 1 Faculty of Psychology, University of Lisbon, Portugal \\ 2 Centre for Disability Studies, University College Dublin, Ireland \\ 3 College of Social Sciences and Law, University College Dublin, Ireland \\ 4 School of Psychology, University College Dublin, Ireland \\ * Correspondence: Dr Flávia H. Santos. Ad Astra Fellow, Assistant Professor at University College Dublin, \\ UCD School of Psychology Dublin, Ireland (D04 V1W8), Email: flavia.santos@ucd.ie ,Tel: +353 17168336
}

\begin{abstract}
Background and Aims: Screening and assessment of cognitive changes in adults with Intellectual Disabilities, mainly Down Syndrome (DS), is crucial to offer appropriate services to their needs. We present a systematic review of the existing instruments assessing dementia, aiming to support researchers and clinicians' best practice. Methods: Searches were carried out in the databases Web of Science; PubMed; PsycINFO in March 2019 and updated in May 2020. Studies were selected and examined if they: (1) focused on assessing age-related cognitive changes in person with ID; (2) included adults and/or older adults; (3) included scales and batteries for cognitive assessment. Results: Forty-eight cross-sectional studies and twenty-six longitudinal studies were selected representing a total sample of 5,851 participants (4,089 DS and 1,801 with other ID). In those studies, we found 38 scales, questionnaires, and inventories, and 13 batteries for assessing cognitive and behavioural changes in adults with DS and other ID. Conclusion: The most used instrument completed by an informant or carer was the Dementia Questionnaire for Learning Disabilities (DLD), and its previous versions. We discuss the strengths and limitations of the instruments and outline recommendations for future use.
\end{abstract}

Keywords: screening; dementia; intellectual disability; early-onset, neuropsychology

\section{Introduction}

Individuals with intellectual disabilities (ID) may be at an increased risk of developing dementia when compared to the general population [1]. In people with ID, the prevalence of dementia is as high as $4 \%$ in individuals under 40 years, and $40 \%$ in those 60 years or older, with an average age of onset between 51 and 56 years [2, 3, 4]. Epidemiological studies found that within a population of 222 individuals with ID aged 60 years, a total of 29 had a dementia diagnosis when using the criteria with both the ICD-10 and DSM-IV [5]. Among those diagnosed with dementia, 66\% of individuals met criteria for dementia of Alzheimer's type, with a prevalence of $8.6 \%$ (95\% CI 5.2-13.0). Recently, a cross-sectional study with 493 adults with Down Syndrome (DS) and other ID reported that individuals with other ID may develop dementia and mild neurocognitive disorder at an earlier age and at a higher rate than the general population. The prevalence of dementia in individuals with other ID was $0.8 \%$ in the age group of 45 to 54 years, 3.5\% in the group of 55 to 64 years and $13.9 \%$ for those aged 65 to 74 years. The study also showed that the prevalence of mild neurocognitive disorder in individuals with other ID was $3.1 \%$ in the age group of 45 to $54,3.5 \%$ in the age group of 
55 to 64 , and $2.8 \%$ for in the age group of 65 to 74 . When analyzed by severity of ID in individuals with DS and other ID, $1.5 \%$ of the individuals classified as moderate ID were diagnosed with dementia, $5.0 \%$ classified as severe ID were diagnosed with dementia in relation to $3.0 \%$ of individuals classified as moderate ID and $1.7 \%$ classified as severe ID were diagnosed with mild neurocognitive disorder [6].

Pathological studies also provide evidence for early-onset dementia. By the age of 40 years, nearly all individuals with Down Syndrome (DS) presented Alzheimer's Disease (AD) markers [7] and longitudinal studies show that by the age of 65 years, dementia in people with DS and other ID exceeds 90 per cent [8;9]. Another study carried out with individuals with DS and other ID ( $n=526)$ showed that among individuals with a diagnosis of DS, symptoms of dementia appeared earlier than those in other ID (average around 52 years of age). In $75 \%$ of the cases, the symptoms were consistent with dementia of Alzheimer's type [10].

Early detection of dementia can be challenging in individuals with ID [11], many of the instruments for assessing dementia-related cognitive changes in the general population are based on the assumption of sound premorbid cognitive functioning, which is difficult to determine in those with ID $[12,13,14]$. Furthermore, the clinical presentation of dementia in those with ID may differ compared to the general population, with personality and behavioural changes presenting earlier [15, 16].

Single domain cognitive tests are the usual approach to screen for dementia in the general population, as they indicate progressive deterioration in cognitive domains [17]. However, in people with ID, these tests are not appropriate due to pre-existing conditions which makes it more difficult for them to perform meaning the results cannot be interpreted in a substantial and valid way, as there are often no norms for this population [11]. This has been addressed in recent research carried out by Benejam [18], who used the CAMCOG-DS in people with Down syndrome to accurately diagnose Alzheimer's disease. This shows the importance of developing reliable population norms for appropriate instruments when assessing cognitive changes in people with ID.

\subsection{Down Syndrome Intellectual Disability}

Among adults with ID, there is a well-established link between Down syndrome and dementia, particularly Alzheimer's disease (AD). Research indicates that 95\% of people with DS will develop AD by the age of $65[4,19,20]$. Individuals with DS also have an increased risk of developing earlyonset dementia; the clinical presentation of dementia symptoms before the age of $65[4,19,21]$. The increased prevalence of AD in DS is largely due to genetic factors associated with trisomy 21, the most common form of DS. Those with trisomy 21 have a third copy of chromosome 21 [22], which is responsible for the production of $\beta$-amyloid precursor protein [23]. The increased presence of $\beta$ amyloid precursor protein leads to an accelerated build-up of senile plaque in the brain, which is a primary cause of $\mathrm{AD}$ [22]. By age 40, most individuals with DS display neuropathological changes consistent with AD, while most individuals with DS show clinical signs of dementia by age 50 [24]. Similarities of symptoms between AD and DS suggest common risk factors among AD and DS. Prasher and colleagues (2008) [25] examined Apolipoprotein (APOE) genotyping in people with DS, concluding that those with APOE E4 allele had a significantly higher risk of developing AD, had an earlier onset of $\mathrm{AD}$, and a higher rate of progression to death when comparing for participants with APOE 3 allele. Screening for APOE genotype in this population may be of good clinical utility as it 
helps people obtain early treatment, which can reduce early mortality rates [25, 26]. Startin et al. (2019) [27] recently "conducted the largest cognitive study to date" (p.245) with 312 participants with DS in order to assess typical age-related and AD-related cognitive changes in this population. The authors reported memory and attention measures were most sensitive to decline, although the earliest cognitive markers of AD-related pathology were identified on most outcome measures. They also reported an age-related relationship where older age groups showed poorer performance in neuropsychological tests, except for scores on the Behaviour Rating Inventory of Executive Function - adult version; a measure of executive function. However, other research has indicated that declines in executive function may precede memory loss in those with DS and AD [28], suggesting further research is needed to determine the typical progression of $\mathrm{AD}$ in this population.

\subsection{Other Intellectual Disability}

There is less conclusive evidence of an increased risk of dementia in those with an intellectual disability not related to DS (herein other ID). While there may be several genetic factors, leading to increased risk of dementia in those with other ID - such as reduced baseline cognitive ability and fewer neurons and synaptic connections [1] - older adults with other ID show protective factors against developing dementia, including lower rates of smoking and greater cardiovascular health compared to the general population [29].

Some research suggests the prevalence of dementia for individuals with other ID may be the same or slightly higher than the general population [30,31], although a longitudinal study by Strydom et al. (2013) [1] reported that dementia might be five times more prevalent in this population. However, epidemiological studies may underestimate true prevalence rates due to several factors. Firstly, dementia is under-diagnosed in the general population - it is likely that this is also present in those with ID [14]. Secondly, those with ID generally have poorer access to health care services [32, 33], which could result in lower levels of diagnosis. Finally, dementia presents differently in those with ID compared to those without, leading to difficulty in diagnosis [14].

\subsection{The present study}

Due to the prevalence of dementia in those with ID, particularly DS, it is important that researchers and clinicians have validated, reliable measures for diagnosis. Standardised measures are necessary for determining prevalence within a population, assessing and comparing interventions, and synthesising research findings for meta-analyses - however, a systematic review by Zellinger et al. (2013) [14] noted an "immense" number of instruments assessing cognitive change in those with ID. The present review aims to build on the previous work by Zellinger et al. (2013) [14] by comprehensively reviewing the existing instruments available for screening for cognitive impairments in individuals with ID, considering cross-sectional and longitudinal studies. This systematic review focuses on scales and batteries as they demonstrate a more robust way to screen for dementia in this population [14,17]. The review will look at the strengths and limitations of instruments and aims to provide researchers and clinicians with an up to date, comprehensive list of available tools. 


\section{Materials and Methods}

The methods for this review were based on the recommendations of the Preferred Reporting Items for Systematic Reviews and Meta-Analyses [34]. As a complement and extension to the PRISMA protocol, we used the Synthesis Without Meta-Analysis in Systematic Reviews Checklist (SWiM), following the recommendation of the EQUATOR group network ("Enhancing the QUAlity and Transparency Of Health Research") (as seen in https://www.equator-network.org) [35]. Both checklists, quality assessment and eligible studies, are available as supplementary material.

\subsection{Literature Search}

Two systematic literature searches of three databases (Web of Science; PubMed; PsycINFO) were conducted. Searches included the key terms (with the appropriate Boolean operators for each database) "Adult* OR Older adult*"; "Cognit* task OR Cognit* test OR neuropsych* test"; "Instrument* OR Scale OR questionnaire OR screening"; "Dementia"; "Intellectual* Disabilit* OR mental* retar* OR General learn* disabilit*". Filters were applied for the key terms NOT "Child* AND adolesc* AND youth*". Searches were performed with consideration of all articles, without limiting the year of publication or language of publication. Except for two publications, one in Spanish and one in German, both included in the screening phase, all other search results were published in English.

\subsection{Eligibility Criteria and Data Extraction}

The eligibility criteria for the studies included in this systematic review were:

Population: Studies that included adults aged 18 years and older diagnosed with Intellectual Disability;

Intervention: Screening of cognitive changes in adults with Intellectual Disabilities;

Comparators: Studies using scales and batteries to assess cognitive changes and dementia in individuals with intellectual disabilities including Down Syndrome

Outcomes: Studies assessing cognitive and behavioural changes in adults with intellectual disabilities

Studies: Studies with cross-sectional and longitudinal designs.

During the first search in March 2019, 70 articles were found on Web of Science, 76 on PubMed, and 60 on PsycINFO ( $n=206)$. Duplicated records $(n=63)$ were removed, leaving 143 articles. A second search for new entries to databases using the same key search terms was done in September 2019 and 58 new entries were found. The search was repeated in May of 2020 and no new articles were identified.

All 201 titles and abstracts were screened using the following inclusion criteria: (1) studies focusing on assessment of dementia in person with ID; (2) population being adults and/or older adults; (3) studies including scales and batteries for cognitive assessment. Sixty-one articles were excluded based on exclusion criteria (review studies and/or intervention studies, or the age of participants not matching the criteria). In total, 140 articles were included for a thorough review (as shown in Fig. 1.). A manual search of the reference sections of the retrieved studies and review articles was conducted. However, no new articles meeting the inclusion criteria were found. 
We analysed 48 cross-sectional studies and 26 longitudinal studies qualitatively, excluding 66 articles for not meeting inclusion criteria (e.g., review studies, intervention studies, and studies including children or adolescents). In total, 74 articles were included in this review. All articles were reviewed by two researchers independently. In the few cases of disagreement, discrepancies were solved by consensus.
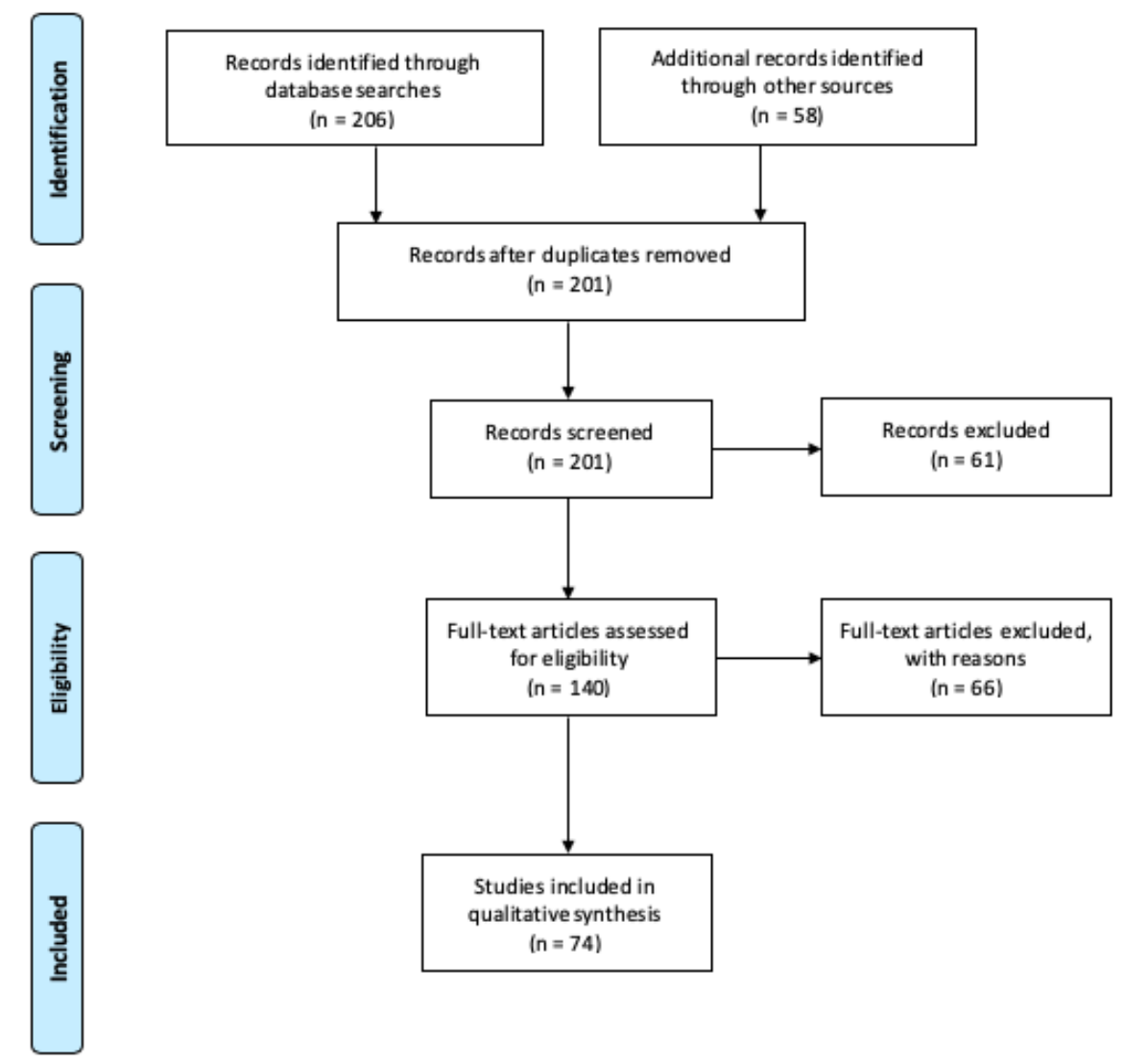

Figure 1. Preferred reporting items for systematic review and meta-analysis (PRISMA) flow chart concerning study retrieval and selection.

\subsection{Quality Assessment}

As for critical appraisal of the studies included in this review, a standardised checklist to identify the risk of bias was used to assess the quality of included studies. The checklist was based on the Newcastle-Ottawa Scale (NOS) [36], embedded on the table A2 and A3. A total score with a maximum value of nine points provides a rating for the quality level. Quality levels of evidence were defined as high (9-7 points); medium (6-4 points), and low (3-1 point). No studies presented low-quality range. 


\section{Results}

\subsection{Descriptive Synthesis}

This review identified 48 cross-sectional studies and 26 longitudinal studies with ID population testing. Cross-sectional studies were conducted in the United Kingdom (13), United States (16), Spain (4), Netherlands (4), Italy (4), Ireland (2), Belgium and Switzerland (1), Australia (2) Israel (1), Finland (1) and Canada (1). Longitudinal studies were conducted in the United States (12), the United Kingdom (7), Ireland and the United States (1), Ireland (1), Germany (1), Canada (1), Australia (1), Spain (1) and the Netherlands (1). The most frequent journal in this review was the Journal of Intellectual Disability Research, with an $\mathrm{H}$ index of 93 and an impact factor of 1.94.

Of the 48 cross-sectional studies, 24 included only participants with DS, while the remaining 24 included individuals with DS and other ID, described in Table 1. The tables for cross-sectional and longitudinal studies (Appendix, Tables A2 and A3) present the characteristics of the participants (age, diagnosis), intervention, comparison, outcomes, and study design [31] structured according to the eligibility criteria. The average duration of longitudinal studies was 99.9 months (sd: 217 months), with no data for one study.

Table 1. Demographics of included individuals in the eligible studies.

\begin{tabular}{cccc} 
Cross-sectional Studies & \multicolumn{2}{c}{ Longitudinal Studies } \\
Down Syndrome & $\mathbf{2 7 7 6}$ & Down Syndrome & 1313 \\
Other ID & 1231 & Other ID & 110 \\
Male & 1396 & Male & 450 \\
Female & 1143 & Female & 1284 \\
Missing data & 1482 & Missing data & \\
Total & & Total & 1844 \\
\hline
\end{tabular}

We found 38 scales, questionnaires, and inventories, and 13 batteries for assessing cognitive and behavioural changes in adults with ID (see appendix B). A total of 22 informant-based measures (scales, questionnaires, and inventories) were used to obtain information on behavioural and cognitive changes from a proxy, while the remaining 29 instruments were self-report measures (13 batteries and 16 scales, questionnaires and inventories). Of the cross-sectional studies included, 15 studies used only self-report instruments, 10 studies used only informant-based instruments, and 15 studies used both type of instruments. Regarding the longitudinal studies, 10 studies used self-report instruments, 5 studies used only informant-based measures, and 6 studies used both types of measures. The remaining studies used single domain tests or tasks (8 cross-sectional studies, 5 longitudinal studies). (see appendix A, tables A2 and A3). According to the selected studies, we identified a multitude of different instruments (single-domain cognitive tests; scales; batteries; tasks), with few replications, and a lack of descriptive data (means, standard deviations, gender ratios, 
specificity and sensitivity scores) in publishing material, which was not obtained from all authors upon request. Consequently, a meta-analysis could not be performed. Of the 26 longitudinal studies, the majority $(n=18)$ focused on DS, while the remainder $(n=8)$ included participants with DS and other ID. There was also a large degree of heterogeneity in measures used in longitudinal studies including those with both DS and other ID. Within the seven studies included, 30 measures and tasks were reported. All datasets generated for this study are included in the article or its supplementary material, including tables 4-7 list of instruments used in the studies, PRISMA checklist and SWiM checklist.

\section{Discussion and Implications}

This study aimed to systematically review scales and batteries for screening for cognitive changes in adults with ID and provide a guide for practitioners and researchers to choose valid, reliable instruments. This review found a multitude of materials used with adults with ID, with much of the research focusing on those with DS. We focused on batteries and scales as the best approach to evaluate cognitive changes and age-related changes in individuals with ID [14, 17]. The current evidence encourages the focus on two measures (DLD and CAMCOG-DS) which should be further explored psychometric, clinic and longitudinally based on the available literature.

Identified instruments can be divided into two categories: informant-based measures (answered by a carer) and self-report measures (answered by the individual). Across the literature, the diagnosis of dementia in this population is a major concern and subject to a disagreement regarding which instrument to use; there is also considerable disagreement surrounding which instruments better discriminate mild neurocognitive disorder and preclinical dementia [8]. Studies are discussed according to the study design and clinical groups.

\subsection{Longitudinal Studies}

\subsubsection{Longitudinal Studies in Participants with Down Syndrome}

The present review identified a multitude of measures used to assess cognitive change in those with DS - 35 separate measures and tasks were used across the 17 studies. The Dementia Questionnaire for Learning Difficulties (DLD - previously referred to as the Dementia Questionnaire for Persons with Mental Retardation, or DMR) $[38,39,40]$ was the most frequently used measure, appearing in six studies [4, 8, 41, 42, 43,44]. The frequent use of the DLD may reflect its recommendation by the National Institute for Health and Clinical Excellence - Social Care Institute for Excellence in the UK [45]. The DLD, an informant-based measure, was developed by Evenhuis (1990) [38] for use with Dutch speakers but has since been translated and used in several countries, allowing cross-cultural comparisons [10, 42, 44,]. The DLD consists of 50 items and eight subscales and provides scores for cognitive and social domains. Previous research has noted that the DLD is widely used due to high levels of agreement between its scores and clinician's diagnosis [46] as well as its good sensitivity and specificity [47].

In the included studies, the DLD was effective in identifying deterioration in cognitive and social skills in adults with DS over time [44], although Nelson et al. (2007) [43] noted that while DLD total scores showed good overall test-retest reliability after one year $(r=.77)$, there was low test-retest 
reliability for the social scale ( $r=.45)$. In another study, [42] using the cognitive element of the DLD as a secondary measure to examine the impact of seizures on cognitive impairment in adults with DS, Lott et al. (2012) [42] found that the cognitive scale of the DLD identified increased deterioration in adults with DS and AD with seizures compared to those without seizures. Similarly, a 14-year longitudinal study by McCarron et al. (2014) [8] found that epilepsy was identified as a significant predictor of dementia in adults with DS and noted the DLD was the most sensitive instrument for tracking cognitive changes over time. However, another study [44] reported that the DLD showed poor sensitivity in distinguishing between dementia-related cognitive decline and depression, which is likely due to the inclusion of the social skills element of the questionnaire. Furthermore, Evenhuis et al. (2009) [39] suggested that this measure may not have adequate sensitivity when used with people with severe and/or profound ID due to a floor effect; similarly, it may also be problematic with those with mild ID due to a ceiling effect on cognitive function.

The Severe Impairment Battery (SIB) [48] is another measure of cognitive functioning which has been used longitudinally. The SIB is a self-report measure assessing cognitive function across nine domains: attention, language, orientation, memory, praxis, visuospatial perception, construction, social skills, and orientating head to name [49]. The SIB was used in 3 longitudinal studies exclusively examining those with DS $[8,41,42]$. Like the DLD, [42] the SIB was effective at tracking the cognitive decline in adults with DS and seizures; it was used as a secondary measure and provides a limited description of its effectiveness $[8,41]$.

\subsubsection{Longitudinal Studies Including Participants with DS and other ID}

There was no overlap between measures used across studies, with no measure included in more than one study. This is illustrative of the lack of standardised measures for assessing cognitive decline in those with other ID and highlights the need for an accepted, recommended measure to allow synthesis across different studies.

It is interesting to note that the DLD was only used in a single study including participants with other ID [10]. The study found that the DLD showed good test-retest reliability within their sample and reported that DLD scores showed agreement with other measures of cognitive change used in their study.

One potentially promising new measure for assessing cognitive decline in those with other ID is the Wolfenbütteler Dementia Test for Individuals with Intellectual Disabilities (WDTIM). The WDTIM was used in a 2-year longitudinal study carried out by Kuske et al. (2017) [50] and was effective at detecting cognitive changes over time. The authors noted that the WDTIM was more effective when used in conjunction with the Dementia Screening Questionnaire for Individuals with Intellectual Disabilities (DSQIID) [51] - an informant-based measure. The combination of a self-report and informant-based measure could provide a useful method to cross-check screening. However, like the DLD, the WDTIM may be problematic when used with individuals with severe and/or profound ID [50]. 


\subsection{Cross-Sectional Studies}

\subsubsection{Cross-Sectional Studies in Participants with Down Syndrome}

As was the case with longitudinal studies, the DLD [38] was the most frequently used instrument, appearing in eight studies [46, 42,53,54,55,56,57]. While the DLD was generally reported as a good marker of cognitive decline and dementia in those with DS, [24], one study found no association between scores on the DLD and the presence of beta-amyloid precursor protein, a biological marker of senile plaques and neurofibrillary tangles present in AD. While this may indicate that the DLD lacks sensitivity in identifying early cognitive changes associated with AD in those with DS, the authors suggest that small sample size and lack of statistical power may have influenced their findings.

The SIB [48] was also frequently used, appearing in four cross-sectional studies [22,53,58,59] Witts and Elder (1994) [59] carried out a preliminary study on the use of the SIB with adults with DS and concluded that the measure was suitable to assess cognitive function in this population. Furthermore, they noted that no floor or ceiling effects were observed in scores on the SIB - this is advantageous as it indicates that the measure can be used to assess cognitive function in a wide range of individuals with ID. A later study [53] reported that the SIB showed good concurrent validity with the DLD. However, unlike Witts and Elder (1994) [59], the authors reported evidence of ceiling effects, which has implications for the clinical usefulness of the measure [53]. They also identified the need for more longitudinal research to determine the effectiveness of the measure over time. Boada [60], using a between-groups design, observed greater impairment in the group with dementia and DS compared to individuals without dementia when using the DLD, but no difference between groups when using the SIB. According to the authors, the DLD is an appropriate functional instrument to assess for dementia in individuals with DS and other ID, while the SIB was not designed for the diagnosis of dementia of Alzheimer's but rather as a measure to monitor cognitive decline in individuals with DS which offers objective function from a clinical view point. Another potential limitation of the SIB is reported by Head et al. (2011) [24], who noted that, like the DLD, there was no association between scores on the SIB and the presence of beta-amyloid precursor protein, which may indicate that the measure lacks sensitivity.

\subsubsection{Cross-Sectional Studies Including Participants with DS and other ID}

The DLD [38,39,40] revealed good psychometric properties in studies with participants with both DS as other ID. Eight studies used the DLD [47,61,62,63,64,65,66,67]. Shultz et al. (2004) [47] reported the sensitivity of the DLD as 0.65 and specificity 0.93 . The instrument was found to be a good marker of the cognitive and affective symptoms observed in the early signs of dementia [65], and displays good inter-test validity with other instruments like the SIB [53] and the Alzheimer's Functional Assessment Tool (AFAST) [63]. The DLD has shown adequate inter-rater reliability for all subscales, except behaviour and disturbance, with correlations of 0.68 or higher [39].

Due to problems with floor and ceiling effects in the assessment of people with ID, researchers have attempted to address this issue. Startin et al. (2016) [56] created a comprehensive neuropsychological assessment to evaluate people with DS and avoid ceiling and floor effects. The LonDownS Consortium identified a set of tests for the evaluation in people with DS with minimum 
floor and ceiling effects. The authors suggest that the battery is suitable for most adults with DS, although half the participants with both dementia and DS were unable to undertake any of the cognitive tasks in the battery, indicating that it may be useful for screening before the development of dementia [56].

Another measure was The Cambridge Cognitive Examination (CAMCOG). This was originally designed for use with the general population but was later adapted for the assessment of dementia in those with DS (CAMCOG-DS) [68]. Cross-sectional studies have shown that this instrument can reliably differentiate between older and younger participants, is useful when possible dementia is considered and shows good internal reliability (Cochran's alpha between 0.82-0.89 and test-retest reliability $(r=.86)$ [69]. When comparing CAMCOG-DS scores in a sample of DS participants between 30 to 65 years old, a significant difference was found in the cognitive performance between younger participants (30-44 years old) and older participants ( $>45$ years old), except on the Attention/Calculation subscales [69]. This is consistent with the idea that the largest differences between age groups are in memory, praxis, and perception subscales $[69,70]$. The authors found a good correlation between MMSE and CAMCOG-DS scores ( $r=.97)$. This inter-test reliability remained after removing MMSE related items in the CAMCOG-DS and excluding participants who achieved zero scores $(r=.95)$. Furthermore, recent research has identified recommended cut-off points for the CAMCOG based on a normative sample of adults with DS [18]. However, it has been noted that this measure may not be suitable for those with severe learning disabilities, severe sensory impairments, or advanced dementia due to floor effects [69]. This instrument has also been found to have "limited diagnostic value as a single assessment" because it is not possible to estimate the extent of the decline in cognitive functioning based on scores - the instrument is also limited at determining whether cognitive decline is due to ID, dementia, or other reasons [67].

There is evidence that the Test for Severe Impairment (TSI) is reliable for monitoring the progression of dementia in people with severe ID [71]. The TSI was used in three of the cross-sectional studies including participants with DS and other ID [61,72,73]. This instrument was developed to assess cognition in people with severe cognitive impairment, and most individuals with moderate/severe ID score on this test and only those with advanced dementia fail to score. In addition to its use in cross-sectional studies, the TSI is reliable and valid in longitudinal studies as it monitors rates of changes and indicates a decline in cognitive function over time that can indicate dementia. In one of the earliest studies using the TSI, [71], the authors assessed the reliability and validity of the instruments in a sample of 60 adults with DS. They found that the convergent validity of the TSI for all samples was good $(r=.94)$, with satisfactory interrater reliability $(r=.97)$ and test-retest reliability $(r=.98)$ over a two-year period. The instrument also showed good internal consistency, with a Cronbach's alpha of 0.89 .

Although DLD has been used in most studies showing it to be effective in identifying changes over time [44] in people with DS and other ID, one study [50] revealed that it may not be an appropriate measure to assess dementia in people with severe ID. Recently, DLD was used in Benejam [18] and as expected, participants with ID with prodromal AD and AD dementia had worse scores than asymptomatic subjects. These authors also recommend cut-off points for the CAMCOGDS for a diagnosis of prodromal AD and AD dementia in adults with DS, based on population norms stratified by level of ID impairment: mild ID, a score of 80 and moderate ID, scores of 56 . 
When screening for cognitive decline in people with ID, we need to highlight and concentrate on the change and decline based on premorbid level of functioning [74]. It is important to keep in mind the ceiling effects of some measures in individuals with DS when compared to severe ID, for example of the SBI, which has implications for the clinical usefulness of the measure [59; 64]. When using the same instrument on individuals with DS when compared to other ID, the TSI can be used in both DS and other ID due to the absence of ceiling and floor effects in individuals with moderate and severe ID, it is a valid and reliable measure to both DS and other ID [71,74].

\subsubsection{Other measures}

Across most studies, the findings suggest that people with ID performed more poorly in verbal tasks, with significant declines with age $[61,75,76,77]$. Phonological tasks are more likely to be sensitive to the detection of cognitive decline among individuals with DS compared to those with other ID, based on significant declines in these tasks [75,78]. This is an important finding when considering which assessment should be used for those with DS and those with other ID.

According to ICD-11 (World Health Organization/2019) and DSM-5, (American Psychiatric Association/2013), the diagnosis of dementia and cognitive changes in the general population and people with ID requires multi domain assessment. Thus, this finding means that phonological tasks are a cognitive marker that should be part of any protocol rather than be taken in isolation $[17,18]$.

Another important aspect of the screening instruments for dementia in ID is their ability to assess the behaviour changes commonly seen during the onset of dementia. An example of this concern is the Assessment for Adults with Developmental Disabilities (AADS) [79]. This instrument assesses prodromal behaviour modifications and deficits associated with dementia in people with ID - such as agitation, stereotypical behaviour, anxiety, or inactivity. The Adaptive behaviour dementia questionnaire $(A B D Q)$ is another instrument specifically developed to assess behaviour changes in those with ID and dementia [6]. The ABDQ was used in two cross-sectional studies [80,81].

\subsubsection{Limitations}

There are some limitations to this review. There is a lack of findings from studies published in other languages. For instance, De Vreese et al. (2011) [62] carried out an Italian adaptation of the AADS (AADS-I) that displays good psychometric properties and satisfactory interrater reliability for the six subscales (coefficients from 0.67 to 0.79 ). A further limitation is the lack of studies found in grey literature and open science databases - while only including papers from peer-reviewed journals helps to ensure the quality of included studies is high, it also limits a large amount of research which may provide additional insights.

Another limitation is the lack of psychometric data for some of the instruments used. Although we aimed to create a review to help clinicians and researchers to find the most suitable instrument, many studies did not provide psychometric properties based on their samples, and we considered it inappropriate to use secondary sources such tests and batteries handbooks, as they do not reflect characteristics of the current samples.

As with any diagnostic assessment, we recommend following practical medical guidelines with multiple diagnostic approaches assessing cognitive, behavioural, and independent functioning. The use of informant and self-report instruments alongside medical examinations, neuroimaging 
techniques, and genetic and biological measures of various types of dementia is also recommended [82].

We found no overlap between measures used across studies, with no measure included in more than one study. The use of the same instruments in different languages would favour cross-cultural comparisons. This is illustrative of the lack of standardised measures for assessing cognitive decline in those with other ID and highlights the need for an accepted, recommended measure to allow synthesis across different studies.

This systematic review could not examine neuropsychological assessment in different stages of dementia due to the nature of the articles selected. There is no consensus regarding dementia stages in people with ID and discrepancies with the general population are observed $[8,63,83]$. This reinforces the need for longitudinal studies to investigate cognitive changes in DS and other ID. Studies as 61 and 84 are promising examples of the benefit of this approach as they use baseline and longitudinal data to support and explore factors related to cognitive decline.

\section{Conclusions}

In conclusion, there are a multitude of instruments being used to screen for cognitive changes associated with dementia in those with ID. This review highlights the variation between measures used across studies and illustrates the need for unified, standardised measures to allow for the synthesis of results in research and greater consistency of diagnosis in clinical practice. Contrasting cross-sectional and longitudinal studies, we recommend the use of specifically designed instruments such as the DLD [14] and the CAMCOG-DS [67] to assess cognitive functioning and behaviour changes related to ID and dementia. The use of measures designed for the general population should be avoided due to their lack of sensitivity in differentiating between those with and without dementia.

Evidence supports the DLD as a promising informant-based screening tool for the diagnosis of dementia since it covers both cognitive and behavioural symptoms [85]. This view is supported by Tyrer et al. [74]. We stress, however, that the DLD is not an instrument for a clear-cut diagnosis, but rather a good screening instrument for follow up assessment which is reliable when used routinely in combination with other objective measures such as, for example, CAMCOG-DS.

Supplementary Materials: The following are available online at www.mdpi.com/xxx/s1, Tables 4-7: List of instruments; PRISMA checklist; Synthesis-without-Meta-analysis-SWiM-Checklist

Author Contributions: AP performed the searches and data extraction. AP and AN carried-out papers selection and drafted the manuscript. CT completed papers' quality assessment. FS contributed with the concept, protocol, and interpretation of findings. The manuscript was critically revised by all authors.

Funding: This research received no external funding.

Conflicts of Interest: The authors declare no conflict of interest. 


\section{Appendix A}

Table A2 Cross-Sectional Studies

Table A3 Longitudinal Studies

Appendix B List of Instruments and acronyms 
Table A2. Cross-Sectional Studies assessing cognitive changes in ID and ID-DS participants.

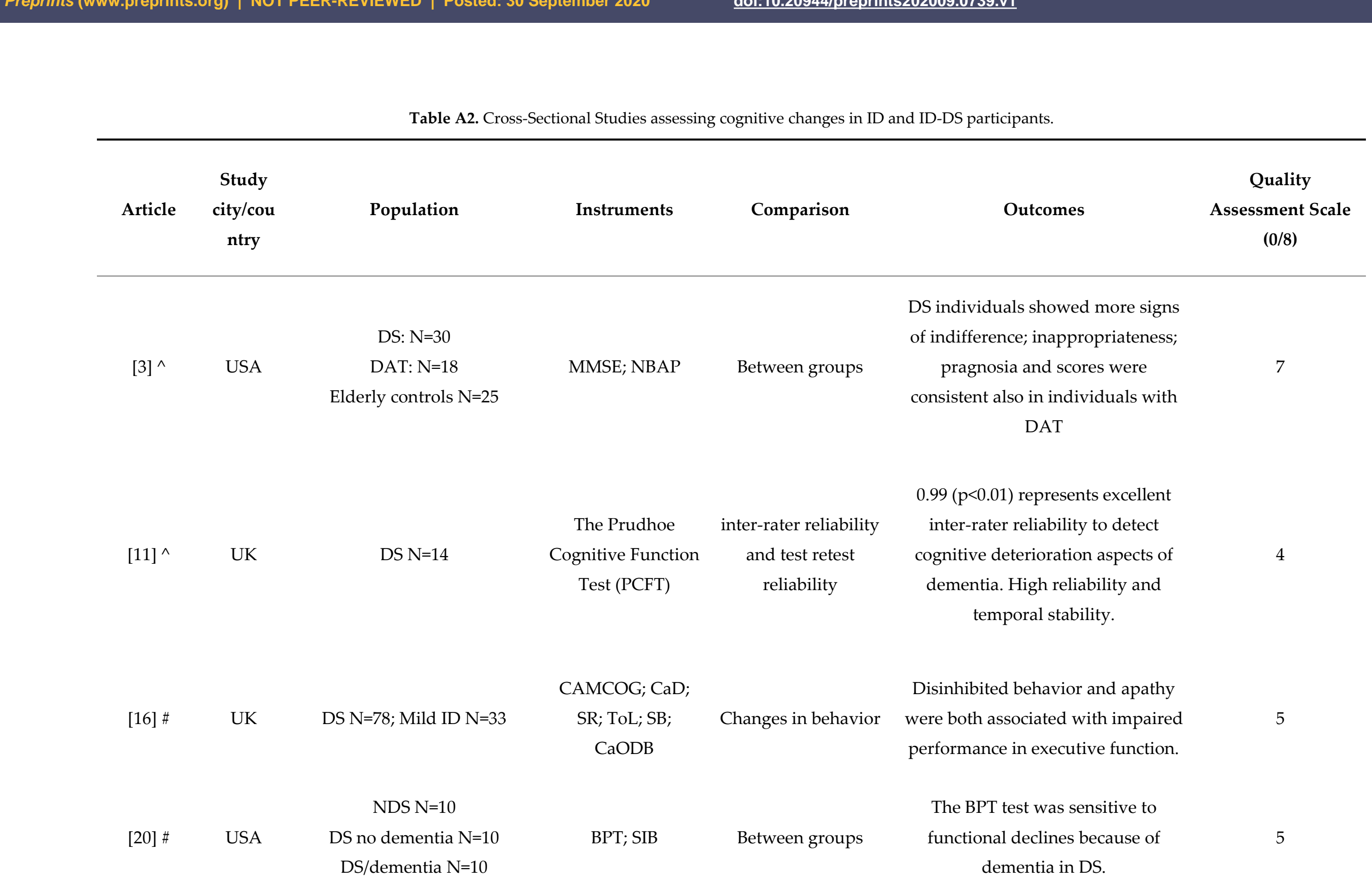




\begin{tabular}{|c|c|c|c|c|c|}
\hline \multirow[b]{2}{*}[24]{$^{*} \#$} & & $\mathrm{DS} / \mathrm{NO}$ AD N=17 & & & \\
\hline & USA & $\begin{array}{c}\text { Normal controls } \mathrm{N}=11 \\
\text { DS/AD N=17 } \\
\text { Normal AD controls N=12 } \\
\text { Group } 2 \\
\text { DS/AD N=52 } \\
\text { DS/NO AD N=78 }\end{array}$ & BPT; SIB; DMR & $\begin{array}{c}\text { Between groups A } \\
\text { beta levels in plasma }\end{array}$ & $\begin{array}{l}\text { No association between plasma } \mathrm{A} \beta \\
\text { and scores on the SIB and DMR; } \\
\text { Lack of sensitivity of SIB and DMR } \\
\text { to detect dementia or cognitive } \\
\text { decline in DS adults. }\end{array}$ \\
\hline$[46]^{*}$ & UK & $\begin{array}{c}\text { Ntotal }=62 \text { DS } \\
\text { N=26 DS/dementia } \\
N=36 \text { DS no dementia }\end{array}$ & $\begin{array}{l}\text { MMSE; DMR; } \\
\text { DSDS }\end{array}$ & Between instruments & $\begin{array}{l}\text { Positive correlation in the diagnosis } \\
\text { of dementia between DMR and the } \\
\text { DSDS with specificity and } \\
\text { sensitivity at } 0.92 \text { in both cases. }\end{array}$ \\
\hline$[47]^{*}$ & USA & $\begin{array}{c}\text { ID N=38 } \\
\text { ID/DS N=26 } \\
\text { ID with dementia } \mathrm{N}=19 \\
\text { ID no dementia } \mathrm{N}=19\end{array}$ & $\begin{array}{l}\text { DSDS; DMR; Reiss } \\
\text { Screen; Shultz } \\
\text { MMSE }\end{array}$ & Between groups & $\begin{array}{c}\text { Both DSDS and DQMR assess } \\
\text { similar elements of dementia; Both } \\
\text { subscales of DSDS differentiated } \\
\text { between groups }\end{array}$ \\
\hline$[52] * \#$ & $\begin{array}{c}\text { Netherla } \\
\text { nds }\end{array}$ & DS N=39 & $\begin{array}{l}\text { WPPSI-R; FANT; } \\
\text { NPEMID; DMR; } \\
\text { SRZ/SRZ-P; FP/FS }\end{array}$ & Between instruments & $\begin{array}{l}56 \% \text { of participants preferred facial } \\
\text { pictograms scales over drawn face } \\
\text { stimuli }\end{array}$ \\
\hline
\end{tabular}




$\begin{array}{ccc} & \text { DS N=90 (mean age 38.97, } \\ & \text { SD } \pm 9.18 \text { ) } \\ & \mathrm{N}=37 \text { males; } \\ \mathrm{N}=16 \text { females } & \text { SIB; DMR }\end{array}$

The

DS N=106 (mean age=37; n=56
[54]* \# Netherla
nds
DS/possible dementia $\mathrm{N}=49$
(age range $=40$ years and over)

SRZ/SRZ-P ; DMR ;

FAS ; CAS ; NRS

Between instruments
SIB vs DMR criterion validity

WAIS-III; DMR;

$[55]^{*}$ \# USA DS N $=20$
Between instruments
The SIB has good concurrent criterion validity when compared to DMR; The SIB has a good validity specifically as a measure of cognitive ability in people with DS: It correlates only with the cognitive functioning component of the DMR.

Adults with DS have generally a better comprehension of faces rather than numbers and more comprehension of pain affect rather than pain intensity.

\section{DMR is the strongest predictor of} reversal learning error scores, suggesting symptoms of dementia effect on reversal learning
WGTA; Tasks:

ODL, RL; DNMP;

DNMS 


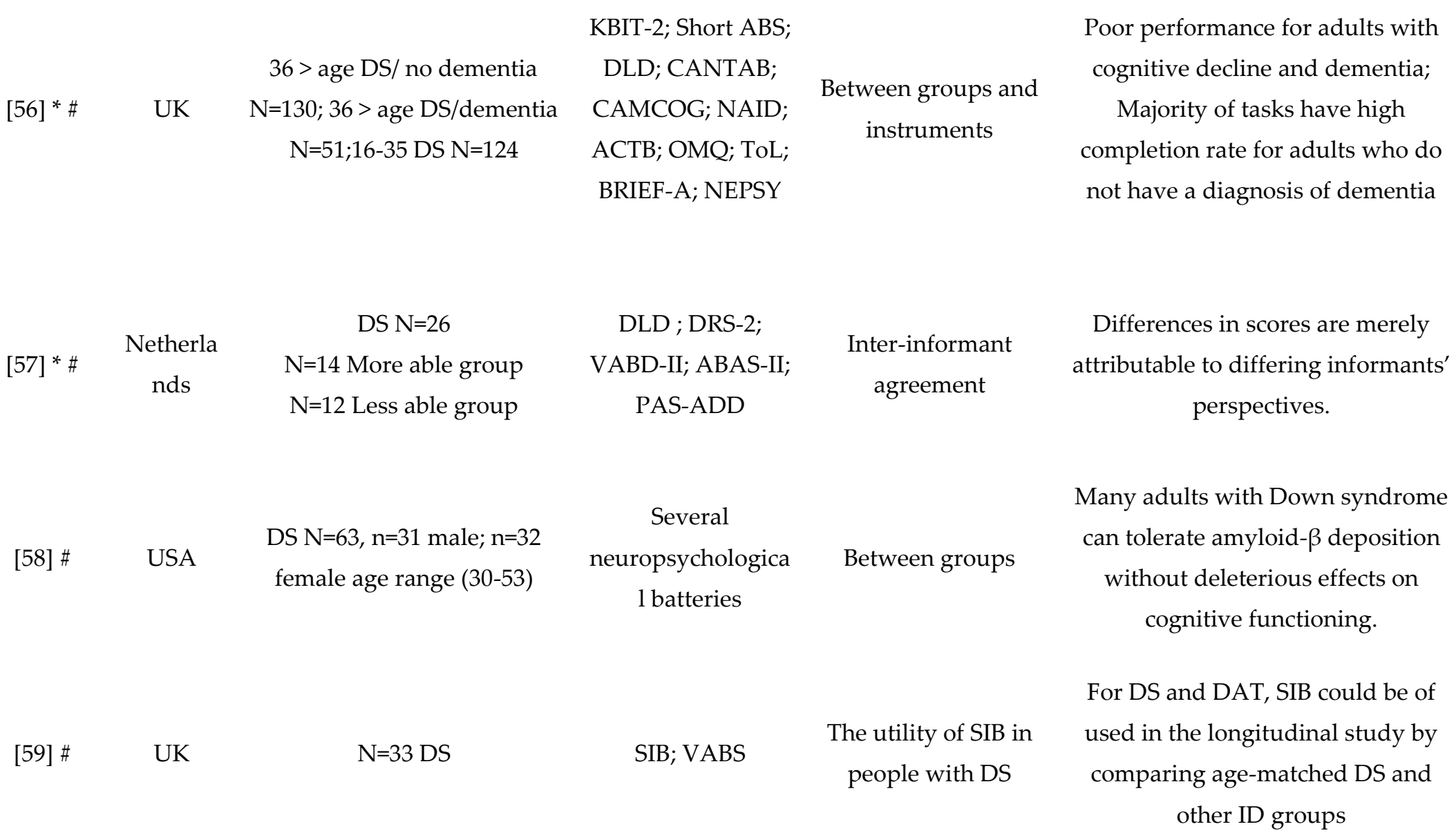




\begin{tabular}{|c|c|c|c|c|c|}
\hline$[61]^{*} \#$ & USA & $\begin{array}{c}\text { DS N=55; } \\
\text { NDS N=75; }\end{array}$ & $\begin{array}{c}\text { BVSR; PPVT; } \\
\text { SICD-AASH; LIPS; } \\
\text { BSID; TSI-M; PP; } \\
\text { DTVMI; DSADS; } \\
\text { DSDS; DMR; SoIB; } \\
\text { RSMB; PIMRA; } \\
\text { DASH-II; DSI; } \\
\text { MAS }\end{array}$ & $\begin{array}{c}\text { Between groups and } \\
\text { age groups }\end{array}$ & $\begin{array}{l}\text { Performance of older adults did not } \\
\text { change over time, but that of } \\
\text { younger adults with DS and adults } \\
\text { without DS improved; Adults with } \\
\text { DS showed significant and unique } \\
\text { declines only in test of verbal } \\
\text { fluency }\end{array}$ \\
\hline$[62]^{*}$ & Italy & $\begin{array}{c}\text { ID N=63 } \\
\text { ID/DAT N=15 } \\
\text { DAT/DS N=13 }\end{array}$ & $\begin{array}{l}\text { Italian translation } \\
\text { of the AADS scale } \\
\text { (AADS-I) DMR }\end{array}$ & & $\begin{array}{c}\text { Subjects with DAT scored } \\
\text { significantly higher on both DMR } \\
\text { subscales compared to the subgroup } \\
\text { without DAT }\end{array}$ \\
\hline$[63]^{*}$ & Italy & $\begin{array}{c}\text { ID N=61 } \\
\text { ID/DS N=22 } \\
\text { ID/NDS N=39 }\end{array}$ & $\begin{array}{l}\text { AFAST; ADL; } \\
\text { IADL; DMR }\end{array}$ & $\begin{array}{l}\text { AFAST-I clinical } \\
\text { significance }\end{array}$ & $\begin{array}{c}\text { Good internal consistency of the } \\
\text { AFAST-I (.92); AFAST-I assesses } \\
\text { several difficulty levels of } \\
\text { autonomy. }\end{array}$ \\
\hline
\end{tabular}

BVSR; PPVT; SICD-AASH; LIPS; BSID; TSI-M; PP DSDS; DMR; SoIB RSMB; PIMRA -II; DSI MAS AFAST; ADL;
Performance of older adults did not
change over time, but that of
younger adults with DS and adults
without DS improved; Adults with
DS showed significant and unique

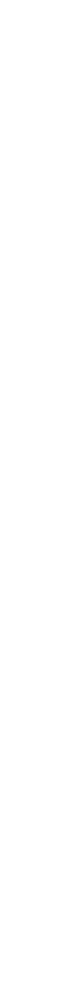
$\mathrm{ID} / \mathrm{DS} \mathrm{N}=22$ ID/NDS N=39

\section{ID/DAT $=15$}

(n)

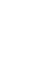

Good internal consistency of the
AFAST-I (.92); AFAST-I assesses 


\begin{tabular}{|c|c|c|c|}
\hline$[64]^{*} \#$ & Spain & $\begin{array}{c}\text { ID N=146; Mild ID N=62; } \\
\text { Moderate ID N=84; } \\
\text { ID/DS N=103, ID/NDS N=43; }\end{array}$ & $\begin{array}{l}\text { DMR; K-BIT I; } \\
\text { CAMDEX-DS; } \\
\text { CAMCOG-DS }\end{array}$ \\
\hline$[65]^{*}$ & Italy & $\begin{array}{c}\text { N=58 DS; } n=40 \text { no dementia; } \\
\text { n3=dementia } \\
\text { N=142 NDS, } n=126 \text { no } \\
\text { dementia; } n=2 \text { dementia }\end{array}$ & DSQIID; DMR \\
\hline$[66]^{*}$ & UK & $\begin{array}{c}\text { ID/NDS N=76 } \\
\text { DS N=12 }\end{array}$ & DMR; ABS \\
\hline$[67]^{*} \#$ & USA & $\begin{array}{c}\mathrm{N}=63 \text { men; } \\
\text { mild ID N=40; moderate ID } \\
\mathrm{N}=44 \text {; severe and profound ID } \\
\mathrm{N}=30 ; \text { ID/DAT } \mathrm{N}=71 ; \mathrm{ID} / \mathrm{no} \\
\text { DAT N=43 }\end{array}$ & $\begin{array}{l}\text { RADD; DMR; } \\
\text { BADLS; SIB; BP }\end{array}$ \\
\hline
\end{tabular}

Between instruments

Between instruments

Reliability of the DSQIID-I was 0.94;

High degree of diagnostic validity between the CAMDEX-DS and the CAMCOG- DS; Reliability scored

0.93 .

\section{DMR gives a general indicator of} Between instruments

cognitive and affective symptoms that could indicate dementia.

RADD has efficacy for assessing cognitive functions relevant to $\mathrm{AD}$ in DS; RADD differentiated participants based on their dementia status 


\section{$\mathrm{N}=77$ DS}

[69] \#
Group 1 age 30-44 ( $N=45)$

UK Group 2 age 45 years and over

$$
(\mathrm{N}=29)
$$

\section{CAMCOG; MMSE Between instruments}

\section{Moderate ID group:}

ID/dementia $\mathrm{n}=19$

[71] \# Ireland

\begin{abstract}
ID/no dementia $\mathrm{n}=29$
\end{abstract}
Severe ID group:

ID/dementia $\mathrm{n}=11 \mathrm{ID} / \mathrm{no}$

dementia $\mathrm{n}=11$

[72] * Ireland

\author{
No DAT/DS N=14 DS/DAT
}

$$
\mathrm{N}=16
$$

CAS-ID; DSMSE;

TSI; DLSQ

DAT N $=13$

$[73]^{\wedge}$

USA

OMT; TSI; ABMT;

O; PRT; NEPSY;

Normal controls $\mathrm{N}=31$ PPV-III

Younger group scored higher in the total CAMCOG and MMSE scores

on all subtests except

Attention/Calculation; CAMCOG

can be used when possible dementia is being considered.

The TSI is useful to monitor the progression of dementia longitudinally in severe MR. TSIReliability 0.89 .

Good measure cognitive and functional decline in individuals with DS and AD.

The functional level of the DAT group was significantly lower than that of the normal control group; DAT groups scores significantly lower than the normal group; 
Tasks: VS; MN;

[75]^ ${ }^{\wedge} \quad$ Canada $\quad \mathrm{N}=31 \mathrm{DS}$ N=41 NDS

DS young: $\mathrm{N}=16$

[76] \# USA

DS old: $\mathrm{N}=16$

NDS young: $\mathrm{N}=16$

NDS old: $\mathrm{N}=15$

Dementia N=10

$[77]^{*} \quad$ USA

$\mathrm{DS}=6 ; \mathrm{ID} / \mathrm{NDS}=4$

No dementia $\mathrm{N}=12$

$\mathrm{DS}=4 ; \mathrm{ID} / \mathrm{NDS}=8$

$[78]^{\wedge} \quad$ Finland

DS: $\mathrm{N}=15$ group

ID/NDS: N=15
RA; NF; SAE; CO;

WR; FM; Matrices

WAIS or WAIS-R;

Stanford-Binet

ratio IQ; DRS;

PPVT-R- Form M;

MAT; CAS

CTT; BNT;

TCOWAT; FOME; ESDCL NWR; NWS; DSF; $\mathrm{CB}$; VST
Tasks: DSB; CS;
People with DS performed poorly in two verbal tasks; Phonological tasks are more likely to be sensitive in the detection of cognitive decline among people with DS

DS old group performed poorly in most test. In the tasks that involved verbal output both DS groups performed poorly

Deficits in the Dementia group in areas consistent with diagnosis of dementia for persons with ID

The DS group performed significantly more poorly in working memory tasks that measured phonological loop working memory performance 
$[80]^{*} \quad$ Australia

DS=33

$\mathrm{N}=55$ total;

[81] *

Australia

DS N=47; AD or suspected: $\mathrm{N}=10$

Switzerla

[86] \#

nd \&

Belgium

DS $\mathrm{n}=28$

[87] \#
USA
PPVT-4; DBC-A;

ABDQ; ABAS-II

ABDQ; RCPM;

PPV; ASM; VSM;

TACL-III

PPVT-R, Block

Pattern subtest of

HNTLA; WISC-R;

BDDE; DSF; OPS;

BTS; DS
Age is associated with decrease in adaptive behavior independent of dementia and health status; Agerelated changes are domain specific rather than pervasive

Adults with DS may show failure in continuing developing in productive syntax.

Dissociation between productive and receptive vocabulary measures in verbal short-term memory abilities in DS participants. knowledge verbal abilities

Older patients with DS with The relation of EEG alpha background to cognitive function decreased alpha waves backgrounds had fewer visuospatial skills, decreased attention span, and dementia 


\begin{tabular}{|c|c|c|c|c|}
\hline [89] \# & UK & $\begin{array}{c}\mathrm{N}=70 \mathrm{DS} ; \mathrm{n}=39 \text { female, } \mathrm{n}=31 \\
\text { male. }\end{array}$ & $\begin{array}{l}\text { BPVS; VABS; } \\
\text { CAMDEX;ECT }\end{array}$ & Between age groups \\
\hline$[90]^{*} \#$ & UK & $\begin{array}{c}\text { N=63 DS; } \\
\text { N=74 NDS; } \\
\text { Mild ID n=27; Moderate ID } \\
\text { n=69; Severe ID n=38; } \\
\text { profound ID n=4 }\end{array}$ & DQ; IBR-MSE & Between instrument \\
\hline [91]\# & USA & $\begin{array}{c}\text { ID/NDS N=40 } \\
\text { ID/DS:Healthy N=44 } \\
\text { Questionable DAT N=10 } \\
\text { Early-Stage DAT N=5 }\end{array}$ & WISC-R; CRT; SRT; & $\begin{array}{l}\text { Levels of decline } \\
\text { across stages of } \\
\text { dementia }\end{array}$ \\
\hline
\end{tabular}

Middle-Stage DAT N=7
$[92]^{*} \#$

\section{DS N=48}
Control group NDS N=42 CAMCOG; BPVS Between groups
Participants with highest risk of developing dementia scored significantly higher in identification

test

\section{Good agreement between DQ and the IBR Mental Status Exam;}

\section{Disagreement is greater for} individuals who are lower

functioning and for those with DS

Group differences: (i.e. healthy with DS, 'questionable', early-stage dementia and middle-stage dementia) for each subtest

Significant negative correlation between mean myo-inositol concentration and overall cognitive ability in DS group 


\begin{tabular}{|c|c|c|c|c|}
\hline$[93]^{\wedge}$ & USA & $\begin{array}{c}\text { DS } n=53 \\
\text { Williams syndrome } n=10 \\
\text { Mixed etiology } n=39\end{array}$ & $\begin{array}{l}\text { Short term } \\
\text { memory and dual } \\
\text { task processing } \\
\text { tasks }\end{array}$ & Between groups \\
\hline$[94]^{\wedge}$ & USA & $\begin{array}{c}\text { DS N=9 } \\
\text { NDS N=24 } \\
\text { DAT/ DS N=15 } \\
\text { DAT/NDS N=11 }\end{array}$ & $\begin{array}{l}\text { r- PRMT; OMT; } \\
\text { TSI; NEPSY }\end{array}$ & Between groups \\
\hline$[95]^{*}$ & USA & $\begin{array}{c}\text { DS N=14 } \\
\text { Typically, Development N=82 } \\
\text { WS } \mathrm{n}=41\end{array}$ & DLD; KBIT & Between groups \\
\hline$[96]^{\wedge}$ & Spain & $\begin{array}{c}\text { DS/no DAT N=75; } \\
\text { DS/DAT N=15 }\end{array}$ & $\begin{array}{c}\text { Modified Cued } \\
\text { Recall Test (mCRT) }\end{array}$ & Between groups \\
\hline [97] \# & UK & $\begin{array}{c}\text { DS Total } \mathrm{N}=49 \\
\text { DS/dementia } \mathrm{N}=19 \\
\text { DS/no dementia } \mathrm{N}=30\end{array}$ & $\begin{array}{l}\text { ACTB; CANTAB; } \\
\text { NAID; ToL; VF; F- } \\
\text { NT; GA; OM }\end{array}$ & АСТВ validity \\
\hline
\end{tabular}

Dual task performance declined significantly in DS; No aetiology group differences on single tasks.

The r-PRMT discriminates between those with DAT from those without DAT; Controls with DS showed higher scores.

\section{Individuals with DS demonstrated} age-related effects on gray matter associated with dementia

Healthy DS achieved higher total scores and committed fewer intrusion errors; In DS- DAT with advanced DAT the mCRT is not useful.

Only 3 tests of the ACTB differentiated between demented 
$[98]^{*}$ \# $\quad$ UK $\begin{gathered}\text { Total DS N=128 } \\ \text { DS/Dementia N=23/128 }\end{gathered}$

[99] \# Israel

ID/DS N=65/69

[100] \# Spain $[101]^{*} \quad \begin{gathered}\text { Netherla } \\ \text { nds }\end{gathered}$

$[102]^{*}$ \# Spain
NSD N=18;

DS N=14;

ID N=69 DS N=224

CSDS; CAMDEX; KBIT-2

LLPI; PPVS; RSPM; PFT; S; CVMT; IC; TFB; HMGT; MTT; NVMT; TMT

K-BIT; CANTAB; WAIS-III; SFWGT; WCFST; TOLDx N=93; VNTR-DAT1 $\mathrm{N}=57$ DS $\mathrm{N}=63$ adults ID mild $_{N}=39 \mathrm{ID}_{\bmod } \mathrm{N}=24$
PS; DFPA; WPPSI-

R; FANT; NPEMID; FSID

KBIT-2; ABS-RC:2;

CAMDEX-DS; BT-

ID; WCFST; BRIEF; TOLdxrm
Development of CS-

DS

Good reliability (0.84) and validity using two raters and over two time points.

Participation in cognitively stimulating activities influence cognitive performance in adults with ID with and without DS.

Met allele carriers showed worse adaptive social skills and selfdirection.

Structural differences and atypical patterns of brain activation in DS individuals.

Psychometric properties of the TOL ${ }^{\text {Dxtm }}$ version for people with ID were satisfactory on all variables; Sensitivity (0.76), Specificity (0.81). 
Legend: DAT (Dementia of Alzheimer's type); HD (Huntington Disease); MR (Mental Retardation); DS (Down Syndrome); ID (Intellectual Disability); AD (Alzheimer Disease); WS (Williams Syndrome); ID (Intellectual Disability); NSID (Non Specific ID); Cd (Cognitive decline); NDS (Without Down Syndrome) CD (Cognitive Deterioration). For acronyms of instruments (scales, questionnaires investors and batteries) see appendix B and supplementary material; ${ }^{*}$ means the study used an informant based measure; \# means the study used a self-report measures; ${ }^{\wedge}$ single domain tests and tasks.

Table A3. Longitudinal Studies assessing cognitive changes in mixed groups of ID participants.

\begin{tabular}{|c|c|c|c|c|c|c|}
\hline Article & Study city/country & Population & Instruments & Comparison & Outcomes & $\begin{array}{c}\text { Quality } \\
\text { Assessment } \\
\text { Score (0/8) }\end{array}$ \\
\hline$[2 \#]$ & UK & DS N=30 & $\begin{array}{c}\text { Several } \\
\text { multidomain }\end{array}$ & Follow up & $\begin{array}{c}\text { Those with } \\
\text { cognitive } \\
\text { deterioration show } \\
\text { a significant decline } \\
\text { on measures of } \\
\text { executive function } \\
\text { between baseline } \\
\text { and } 16 \text { months } \\
\text { follow up }\end{array}$ & 7 \\
\hline$\left[4^{*} \#\right]$ & Ireland & $\mathrm{N}=77$ & $\begin{array}{l}\text { DLSQ-NIA; DLD; } \\
\text { DSMSE; TSI }\end{array}$ & Follow-up & $\begin{array}{c}\text { Over } 20 \text { years } \\
\text { follow-up, } 97.4 \% \\
\text { developed } \\
\text { dementia }\end{array}$ & 6 \\
\hline$[8$ \# $]$ & Ireland, USA & DS N=77 & $\begin{array}{c}\text { SIB; DSMSE; DLSQ; } \\
\text { DMR }\end{array}$ & Follow-up & $\begin{array}{c}\text { After } 20 \text { years, } 75 \\
\text { individuals } \\
\text { developed }\end{array}$ & 6 \\
\hline
\end{tabular}


dementia at a 20-

year follow-up.

Participants with

DAT had lower

total scores that

ID/NDS N=66;

$\left[9^{\wedge}\right]$

USA

DS/no DAT N=75

DS/DAT N=19

mCRT

Between groups

participants without

$$
\text { DAT; Poor }
$$

performance on the adaptation of CRT

was associated with early-stage DAT.

Equivalent or maybe lower risk

\section{MR/NDS N=117}

DMR; RS; Part I of

MR/DS n=126

AMDAB

Between groups

for dementia

between MR

participants and

general population

People with a

diagnosis of $\mathrm{AD}$ at

[15 \#]

UK

DS N=61

CAMDEX;

Longitudinal

baseline were at

CAMCOG;

comparison

least 6 more times

likely to diagnosed

with $\mathrm{AD}$ at time 2 


\begin{tabular}{|c|c|c|c|c|c|c|}
\hline$\left[41^{*} \#\right]$ & USA & $\mathrm{N}=1$ & $\begin{array}{l}\text { BPT; DMR; SIB; } \\
\text { RADD; WAIS III; } \\
\text { VABS-II }\end{array}$ & Follow-up & $\begin{array}{l}\text { The prevalence of } \\
\text { APP disomy in } \\
\text { patients with DS } \\
\text { resulting from PT21 } \\
\text { appears to be very } \\
\text { rare since only } 2 \\
\text { cases. }\end{array}$ & 7 \\
\hline$[42 * \#]$ & USA & $\begin{array}{c}\text { DS/DAT } \\
\text { No seizure N=29; } \\
\text { Seizure group N=24 }\end{array}$ & $\begin{array}{l}\text { SIB; BPT; DMR; } \\
\text { VABS }\end{array}$ & Between groups; & $\begin{array}{l}\text { Cognitive decline is } \\
\text { more marked in } \\
\text { demented } \\
\text { individuals with DS } \\
\text { who have seizures } \\
\text { compared to those } \\
\text { who do not. }\end{array}$ & 6 \\
\hline$[43 * \#]$ & USA & $\begin{array}{c}\text { DS N=34 } \\
\mathrm{N}=19 / 34 \text { retested } \\
\text { one year later }\end{array}$ & $\begin{array}{l}\text { WAIS-III; NBAP; } \\
\text { DMR; and other } \\
\text { tests }\end{array}$ & $\begin{array}{l}\text { Validity and } \\
\text { reliability of } \\
\text { instruments. }\end{array}$ & $\begin{array}{l}\text { NBAP was the } \\
\text { strongest predictor } \\
\text { of dementia-status. } \\
\text { Strong correlation } \\
\text { between the } \\
\text { pragnosia scale } \\
\text { scores and the DMR }\end{array}$ & 6 \\
\hline$\left[44 \#^{*}\right]$ & UK & $\mathrm{DS}=8$ & $\begin{array}{l}\text { HSSA; DMR; } \\
\text { RCPM; WAIS-R; } \\
\text { MEAMS; }\end{array}$ & $\begin{array}{c}\text { Neuropsychological } \\
\text { assessment }\end{array}$ & $\begin{array}{l}\text { All patients score } \\
\text { below normal } \\
\text { population in } \\
\text { RCPM }\end{array}$ & 6 \\
\hline
\end{tabular}

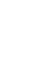


RCPM; BPVS-II;

\section{CAMCOG; DMR Mini PASADD; ABS-CR2}

Longitudinal
comparison

Follow-up
Difficult sensitivity in the DMR to distinguished

between dementia and depression

WDTIM very suitable for mild to moderate ID but limited for severe

ID.

Participants with low scores and deterioration on PCFT and ABS later showed dementia

After 2 years, $38.8 \%$ of participants were diagnosed with dementia.

No significant changes in scores from point to the next in memory, executive function, verbal, visual 
spatial and global scores

\section{Younger DS}

participants,

showed less decline

in full-scale scores;

Cognitive ability, is

more stable over

time in DS sample

The declining group with initial lower scores had lower levels of adaptive behaviour, were

Between

individuals rated as more

a higher frequency

of problem

behaviours.

NDS DS; N=18
PPVT; WISC




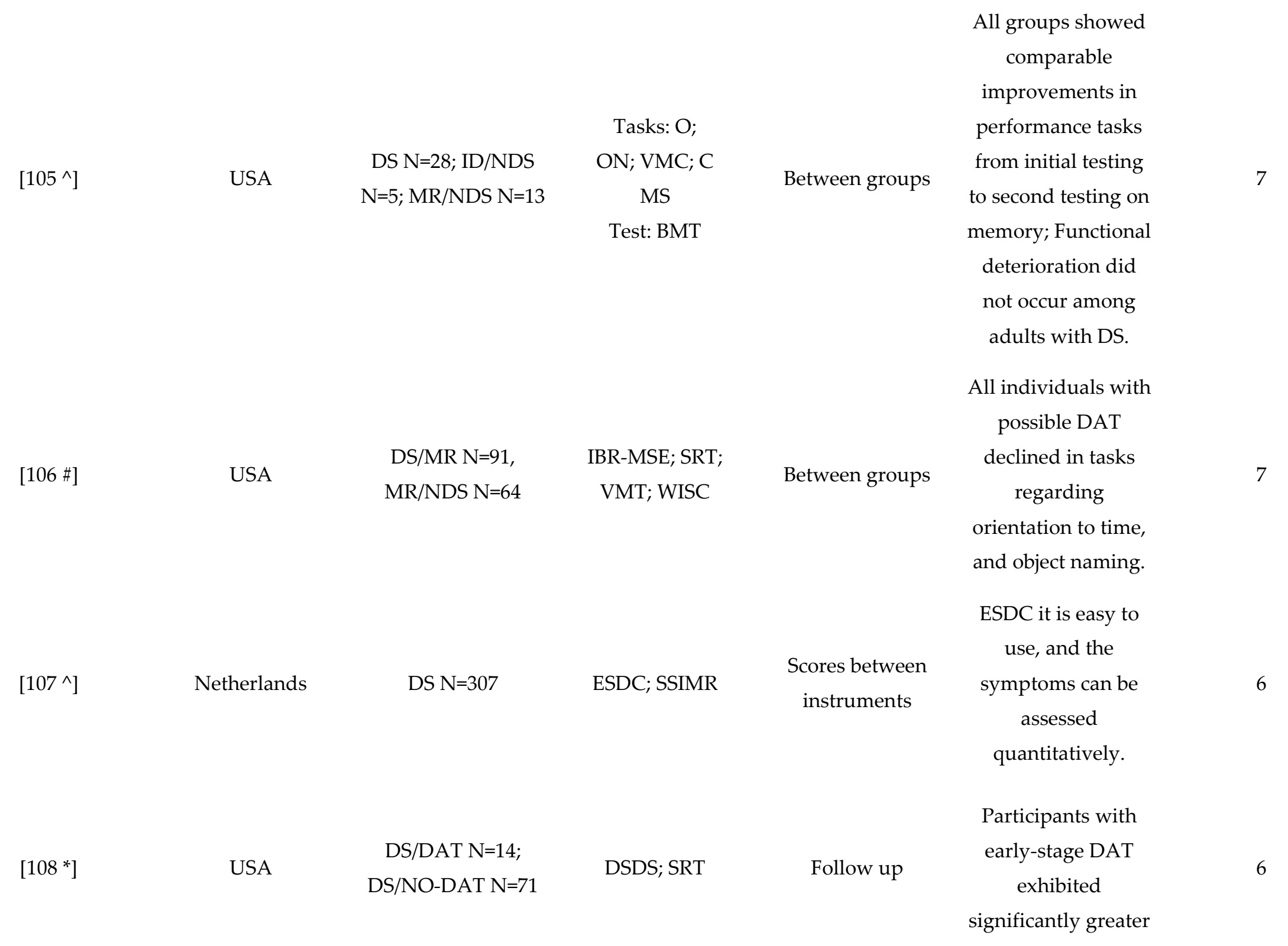




\begin{tabular}{|c|c|c|c|c|c|c|}
\hline & & & & & $\begin{array}{l}\text { decline over the 3- } \\
\text { year period } \\
\text { preceding their } \\
\text { diagnosis; Decline } \\
\text { in SRT } \\
\text { distinguished } \\
\text { between groups. }\end{array}$ & \\
\hline$[110 \#]$ & USA & $\begin{array}{c}\text { ID/NDS N=28; } \\
\text { ID/DS N=42 }\end{array}$ & WISC-R & Sex-related changes & $\begin{array}{l}\text { Male participants } \\
\text { with ID no DS } \\
\text { performed better } \\
\text { than female } \\
\text { participants with ID } \\
\text { NDS; Females with } \\
\text { DS performed } \\
\text { better than males } \\
\text { with ID in object } \\
\text { assembly and block } \\
\text { design }\end{array}$ & 6 \\
\hline$\left[111^{\wedge}\right]$ & UK & DS N=57 & Single domain tasks & Between groups & $\begin{array}{l}\text { Poor performance } \\
\text { and decline in } \\
\text { performance on } \\
\text { delayed response } \\
\text { and conditioned } \\
\text { associative learning } \\
\text { is associated with }\end{array}$ & 6 \\
\hline
\end{tabular}

$\mathrm{D} / \mathrm{NDS} \mathrm{N}=28$;

ID/DS N=42

is associated with

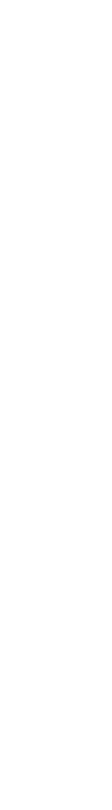


dementia in DS adults.

DS adults who developed DA at early stages showed

DS/DA N=5,

[112 \#]

USA

DS no-dementia

$\mathrm{N}=25$

Multi-domain

Longitudinal
comparison

Time 2 n=28; Mild/moderate ID

Australia

$$
\mathrm{n}=20
$$

Severe/profound ID

$n=8$

PPVT-4; ABDQ;

DBC-A

Follow-up

Follow-up

LIPS; BPVS; WPPSI;
RBMT-C; NAID
DS N=27 of 50
UK

[114 \#] behavioural and
Cognitive changes over a 50-year period progressive

impairment in

selective attention

and in ability to

selectively attend to

stimuli.

Adults with DS may experience

different ageing patterns for

emotional problems

Tests of dementia showed falling off in performance even for those 
without confirmed

dementia

DS-AD groups

showed significant

poorer performance

in all tests,

DS sample $\mathrm{N}=41$;

[115 \#]

Spain

DS-AD n=13; DS-

$\mathrm{MCI} n=14$; DS-

CAMCOG-DS;

Control $n=14$

\section{ADVM; WM; DVM; $\quad$ Between groups}

TO especially in verbal

and working

memory; MCI-DS

showed poorer

performance than

control DS in the

CAMCOG and

DVM.

\footnotetext{
Legend: DAT (Dementia of Alzheimer's type); HD (Huntington Disease); MR (Mental Retardation); DS (Down Syndrome); ID (Intellectual Disability); AD (Alzheimer Disease); WS (Williams Syndrome); ID (Intellectual Disability); NSID (Non Specific ID); Cd (Cognitive decline); NDS (Without Down Syndrome) CD (Cognitive Deterioration). For acronyms of instruments (scales, questionnaires investors and batteries) see appendix B and supplementary material; ${ }^{*}$ means the study used an informant based measure; \# means the study used a self-report measures; ${ }^{\wedge}$ single domain tests and tasks.
} 


\section{Appendix B}

Table 4. List of Scales, Questionnaires and Inventories Table 5. List of Batteries

Table 4. List of Scales, Questionnaires and Inventories

1. Adaptive Behaviour Scale-Residential and Community (ABS)

2. Adaptive Behaviour Assessment System-II Adult (ABAS-II)

3. Adaptive Behaviour Dementia Questionnaire (ABDQ)

4. Alzheimer's Functional Assessment Tool scale for informants (AFAST)

5. Association on Mental Disability Adaptive Behaviour (AMDAB)

6. Bayley Scales of Infant Development (BSID)

7. Behaviour Rating Inventory of Executive Function (BRIEF)

8. Bristol Activities of Daily Living Scale (BADLS)

9. British Picture Vocabulary Scale (BPVS)

10. Caregiver Activity Survey modified (CAS-ID)

11. Cognitive Scale for down Syndrome (CSDS)

12. Daily Living Skills Questionnaire (DLSQ)

13. Dementia Questionnaire (DQ)

14. Dementia Questionnaire for People with Learning Disabilities (DLD/DMR)

15. Dementia Rating Scale (DRS)

16. Dementia scale for Down Syndrome (DSDS)

17. Dementia Screening Questionnaire for Individuals with Intellectual Disabilities (DSQIDD)

18. Developmental Behaviour Checklist - Adult (DBC-A)

19. Diagnostic Assessment for the Severely Handicapped II(DASH II)

20. Down Syndrome Mental State Examination (DSMSE)

21. Dyspraxia Scale for Adults with Down Syndrome (DSADS)

22. Early Signs of Dementia Checklist (ESDCL)

23. Facial Pictograms and Facial Scales (FP/FS)

24. Functioning Scale for Intellectual Disability (FSID)

25. Hampshire Social Services Assessment (HSSA)

26. Instrumental Activities of Daily Living (IADL)

27. Italian translation of the AADS scale (AADS-I) 
28. Later Life Planning Inventory (LLPI)

29. Leiter International Performance Scale (LIPS)

30. Middlesex Elderly Assessment of Mental State (MEAMS)

31. PAS-ADD Checklist

32. Rapid Assessment for Developmental Disabilities (RAAD)

33. Reiss Screen for Maladaptive Behaviour (RSMB)

34. Scales of Independent Behaviour (SoIB)

35. Sequences Inventory of Communication Development for Adolescents and Adults with Severe Handicaps (SICD-AASH)

36. Shultz Mini Mental State Exam (S-MMSE)

37. Social Functioning Scale for Intellectual Disability (SRZ/ SRZ-P);

38. Vineland Adaptive Behaviour Scales (VABS) 
Table 5. List of Batteries

1. ACTB - Arizona Cognitive Test Battery

2. Cambridge Cognition Examination (CAMCOG)

3. CAMDEX (Cambridge Mental Disorders of the Elderly Examination)

4. CANTAB - Cambridge Neuropsychological Test Automated Battery

5. Crayton and Oliver Dementia Battery (CaODB)

6. Das-Naglieri Cognitive Assessment System (CAS)

7. ISADYLE language assessment battery (ISADYLE)

8. NAID object memory and memory for sequences

9. Neuropsychological Test series for Elderly with Mild Intellectual Disability (NPEMID)

10. Severe Impairment Battery (SIB)

11. Wechsler Adult Intelligence Scale (WAIS/WAIS-R)

12. WISC-R (Wechsler Intelligence Scale for Children-Revised)

13. WPPSI-R (Wechsler Preschool and Primary Scale of IntelligenceRevised) 


\section{References}

1. Strydom A, Chan T, King M, Hassiotis A, Livingston G. Incidence of dementia in older adults with intellectual disabilities. Research in developmental disabilities. 2013; 1;34(6):1881-5.

2. Adams D, Oliver C. The relationship between acquired impairments of executive function and behaviour change in adults with Down syndrome. Journal of Intellectual Disability Research. 2010;54(5):393-405.

3. Nelson L, Lott I, Touchette P, Satz P, D'Elia L. Detection of Alzheimer disease in individuals with Down syndrome. American journal on mental retardation. 1995.

4. McCarron M, McCallion P, Reilly E, Dunne P, Carroll R, Mulryan N. A prospective 20-year longitudinal follow-up of dementia in persons with Down syndrome. Journal of Intellectual Disability Research. 2017;61(9):843-52.

5. Strydom A, Livingston G, King M, Hassiotis A. Prevalence of dementia in intellectual disability using different diagnostic criteria. The British Journal of Psychiatry. 2007;191(2):150-157.

6. Takenoshita S, Terada S, Kuwano R, Inoue T, Cyoju A, Suemitsu S, et al. Prevalence of dementia in people with intellectual disabilities: Cross-sectional study. International Journal of Geriatric Psychiatry. 2020;35(4):414-422.

7. Wisniewski KE, Wisniewski HM, Wen GY. Occurrence of neuropathological changes and dementia of Alzheimer's disease in Down's syndrome. Annals of Neurology: Official Journal of the American Neurological Association and the Child Neurology Society. 1985;17(3):278-282.

8. McCarron M, McCallion P, Reilly E, Mulryan N. A prospective 14-year longitudinal follow-up of dementia in persons with Down syndrome. Journal of Intellectual Disability Research. 2014;58(1):61-70.

9. Zis $\mathrm{P}$, Strydom A. Clinical aspects and biomarkers of Alzheimer's disease in Down syndrome. Free Radical Biology and Medicine. 2018;114:3-9.

10. Zigman WB, Schupf N, Devenny DA, Miezejeski C, Ryan R, Urv TK, Schubert R, Silverman W. Incidence and prevalence of dementia in elderly adults with mental retardation without Down syndrome. American journal on mental retardation. 2004;109(2):126-41.

11. Margallo-Lana ML, Moore PB, Tyrer SP, Dawson H, Jenkins K, Kay DW. The Prudhoe Cognitive Function Test, a scale to assess cognitive function in adults with Down's syndrome: inter-rater and test-retest reliability. Journal of Intellectual Disability Research. 2003;47(6):488-92.

12. Nieuwenhuis-Mark RE. Diagnosing Alzheimer's dementia in Down syndrome: problems and possible solutions. Research in Developmental Disabilities. 2009 1;30(5):827-38.

13. Prasher V, Farooq A, Holder R. The Adaptive Behaviour Dementia Questionnaire (ABDQ): screening questionnaire for dementia in Alzheimer's disease in adults with Down syndrome. Research in developmental disabilities. 2004 1;25(4):385-97.

14. Zeilinger EL, Stiehl KA, Weber G. A systematic review on assessment instruments for dementia in persons with intellectual disabilities. Research in developmental disabilities. 2013; 1;34(11):3962-77.

15. Ball SL, Holland AJ, Huppert FA, Treppner P, Watson P, Hon J. The modified CAMDEX informant interview is a valid and reliable tool for use in the diagnosis of dementia in adults with Down's syndrome. Journal of Intellectual Disability Research. 2004;48(6):611-20.

16. Ball SL, Holland AJ, Watson PC, Huppert FA. Theoretical exploration of the neural bases of behavioural disinhibition, apathy and executive dysfunction in preclinical Alzheimer's disease in people with Down's syndrome: potential involvement of multiple frontal-subcortical neuronal circuits. Journal of Intellectual Disability Research. 2010;54(4):320-36.

17. Elliott-King J, Shaw S, Bandelow S, Devshi R, Kassam S, Hogervorst E. A critical literature review of the effectiveness of various instruments in the diagnosis of dementia in adults with intellectual disabilities. Alzheimer's \& Dementia: Diagnosis, Assessment \& Disease Monitoring. 2016; 1;4:126-48.

18. Benejam B, Videla L, Vilaplana E, Barroeta I, Carmona-Iragui M, Altuna M, Valldeneu S, Fernandez S, Giménez S, Iulita F, Garzón D. Diagnosis of prodromal and Alzheimer's disease dementia in adults with Down syndrome using neuropsychological tests. Alzheimer's \& Dementia: Diagnosis, Assessment \& Disease Monitoring. 2020;12(1):e12047.

19. Lin LP, Hsu SW, Hsia YC, Wu CL, Chu C, Lin JD. Association of early-onset dementia with activities of daily living (ADL) in middle-aged adults with intellectual disabilities: the caregiver's perspective. Research in developmental disabilities. 2014; 1;35(3):626-31. 
20. Powell D, Caban-Holt A, Jicha G, Robertson W, Davis R, Gold BT, Schmitt FA, Head E. Frontal white matter integrity in adults with Down syndrome with and without dementia. Neurobiology of aging. 2014; 1;35(7):1562-9.

21. Masellis M, Sherborn K, Neto PR, Sadovnick DA, Hsiung GY, Black SE, Prasad S, Williams M, Gauthier S. Early-onset dementias: diagnostic and etiological considerations. Alzheimer's Research \& Therapy. 2013;5(1):1-22.

22. Head E, Powell D, Gold BT, Schmitt FA. Alzheimer's disease in Down syndrome. European journal of neurodegenerative disease. 2012;1(3):353.

23. Rumble B, Retallack R, Hilbich C, Simms G, Multhaup G, Martins R, Hockey A, Montgomery P, Beyreuther $\mathrm{K}$, Masters CL. Amyloid A4 protein and its precursor in Down's syndrome and Alzheimer's disease. New England Journal of Medicine. 1989; 1;320(22):1446-52.

24. Head E, Doran E, Nistor M, Hill M, Schmitt FA, Haier RJ, Lott IT. Plasma amyloid- $\beta$ as a function of age, level of intellectual disability, and presence of dementia in Down syndrome. Journal of Alzheimer's Disease. 2011; 1;23(3):399-409.

25. Prasher VP, Sajith SG, Rees SD, Patel A, Tewari S, Schupf N, Zigman WB. Significant effect of APOE epsilon 4 genotype on the risk of dementia in Alzheimer's disease and mortality in persons with Down syndrome. International Journal of Geriatric Psychiatry: A journal of the psychiatry of late life and allied sciences. 2008; 23(11):1134-40.

26. Rohn TT, McCarty KL, Love JE, Head E. Is apolipoprotein E4 an important risk factor for dementia in persons with Down syndrome? Journal of Parkinson's disease and Alzheimer's disease. 2014; 8;1(1).

27. Startin CM, Hamburg S, Hithersay R, Al-Janabi T, Mok KY, Hardy J, Strydom A, Fisher E, Nizetic D, Tybulewicz V, Karmiloff-Smith A. Cognitive markers of preclinical and prodromal Alzheimer's disease in Down syndrome. Alzheimer's \& Dementia. 2019; 1;15(2):245-57.

28. Lautarescu BA, Holland AJ, Zaman SH. The early presentation of dementia in people with Down syndrome: a systematic review of longitudinal studies. Neuropsychology review. 2017; 1;27(1):31-45.

29. Haveman M, Heller T, Lee L, Maaskant M, Shooshtari S, Strydom A. Major health risks in aging persons with intellectual disabilities: an overview of recent studies. Journal of Policy and Practice in Intellectual Disabilities. 2010;7(1):59-69.

30. Shooshtari S, Martens PJ, Burchill CA, Dik N, Naghipur S. Prevalence of depression and dementia among adults with developmental disabilities in Manitoba, Canada. International Journal of Family Medicine. 2011.

31. Strydom A, Livingston G, King M, Hassiotis A. Prevalence of dementia in intellectual disability using different diagnostic criteria. The British Journal of Psychiatry. 2007;191(2):150-7.

32. Chaplin E, Paschos D, O'Hara J, McCarthy J, Holt G, Bouras N, Tsakanikos E. Mental ill-health and care pathways in adults with intellectual disability across different residential types. Research in Developmental Disabilities. 2010; 1;31(2):458-63.

33. Perry J, Linehan C, Kerr M, Salvador-Carulla L, Zeilinger E, Weber G, Walsh P, Van Schrojenstein Lantmande-Valk H, Haveman M, Azema B, Buono S. The P15-a multinational assessment battery for collecting data on health indicators relevant to adults with intellectual disabilities. Journal of Intellectual Disability Research. 2010;54(11):981-91.

34. Moher D, Liberati A, Tetzlaff J, Altman DG. Preferred reporting items for systematic reviews and metaanalyses: the PRISMA statement. Int J Surg. 2010; 1;8(5):336-41.

35. Campbell M, McKenzie JE, Sowden A, Katikireddi SV, Brennan SE, Ellis S, Hartmann-Boyce J, Ryan R, Shepperd S, Thomas J, Welch V. Synthesis without meta-analysis (SWiM) in systematic reviews: reporting guideline. British Medical Journal. 2020; 16;368.

36. Wells G, Shea B, O'Connell D, Peterson J, Welch V, Losos M, Tugwell P. Newcastle-Ottawa quality assessment scale cohort studies. 2015. http://www. ohri. ca/programs/clinical_epidemiology/oxford. asp. 2014.

37. Bento T. Revisões sistemáticas em desporto e saúde: Orientações para o planeamento, elaboração, redação e avaliação. Motricidade. 2014;10(2):107-23.

38. Evenhuis HM, Eurlings HA, Kengen MM. Dementia questionnaire for mentally retarded persons (DMR): for diagnosis of dementia in mentally retarded people. Hooge Burch Institute for Mentally Retarded People; 1990.

39. Evenhuis HM, Sjoukes L, Koot HM, Kooijman AC. Does visual impairment lead to additional disability in adults with intellectual disabilities?. Journal of Intellectual Disability Research. 2009;53(1):19-28. 
40. Margallo-Lana ML, Tyrer SP, Moore PB. Overview of the neuropsychological assessment of dementia in intellectual disability. Neuropsychological assessments of dementia in Down syndrome and intellectual disabilities; 2009.

41. Doran E, Keator D, Head E, Phelan MJ, Kim R, Totoiu M, Barrio JR, Small GW, Potkin SG, Lott IT. Down syndrome, partial trisomy 21, and absence of Alzheimer's disease: the role of APP. Journal of Alzheimer's Disease. 2017; 1;56(2):459-70.

42. Lott IT, Doran E, Nguyen VQ, Tournay A, Movsesyan N, Gillen DL. Down syndrome and dementia: seizures and cognitive decline. Journal of Alzheimer's disease. 2012; 1;29(1):177-85.

43. Nelson LD, Scheibel KE, Ringman JM, Sayre JW. An experimental approach to detecting dementia in Down syndrome: a paradigm for Alzheimer's disease. Brain and cognition. 2007; 1;64(1):92-103.

44. Thompson SB. A neuropsychological test battery for identifying dementia in people with Down's syndrome. The British Journal of Developmental Disabilities. 1994; 1;40(79):135-42.

45. Prasher VP. Neuropsychological assessments of dementia in Down syndrome and intellectual disabilities. Springer; 2009.

46. Deb S, Braganza J. Comparison of rating scales for the diagnosis of dementia in adults with Down's syndrome. Journal of Intellectual Disability Research. 1999;43(5):400-7.

47. Shultz J, Aman M, Kelbley T, LeClear Wallace C, Burt DB, Primeaux-Hart S, Loveland K, Thorpe L, Bogos ES, Timon J, Patti P. Evaluation of screening tools for dementia in older adults with mental retardation. American journal on mental retardation. 2004;109(2):98-110.

48. Panisset M, Roudier M, Saxton J, Boiler F. Severe impairment battery: a neuropsychological test for severely demented patients. Archives of neurology. 1994; 1;51(1):41-5.

49. Saxton J, McGonigle-Gibson K, Swihart A, Boller F. The Severe Impairment Battery (SIB) manual. Pittsburgh, PA: Alzheimer's Disease Research Center. 1993.

50. Kuske B, Wolff C, Gövert U, Müller SV. Early detection of dementia in people with an intellectual disability-A German pilot study. Journal of applied research in intellectual disabilities. 2017;30:49-57.

51. Deb S, Hare M, Prior L, Bhaumik S. Dementia screening questionnaire for individuals with intellectual disabilities. The British Journal of Psychiatry. 2007;190(5):440-4.

52. de Knegt NC, Schuengel C, Lobbezoo F, Visscher CM, Evenhuis HM, Boel JA, Scherder EJ. Comprehension of pictograms for pain quality and pain affect in adults with Down syndrome. Journal of Intellectual \& Developmental Disability. 2016; 2;41(3):222-32.

53. Hutchinson N, Oakes P. Further Evaluation of the Criterion Validity of the Severe Impairment Battery for the Assessment of Cognitive Functioning in Adults with Down Syndrome. Journal of Applied Research in Intellectual Disabilities. 2011;24(2): 172-180.

54. de Knegt NC, Evenhuis HM, Lobbezoo F, Schuengel C, Scherder EJA. Does format matter for comprehension of a facial affective scale and a numeric scale for pain by adults with Down syndrome? Research in Developmental Disabilities. 2013;34(10): 3442-3448.

55. Nelson L, Johnson JK, Freedman M, Lott I, Groot J, Chang M, Head E. Learning and memory as a function of age in Down syndrome: A study using animal-based tasks. Progress in Neuro-Psychopharmacology \& Biological Psychiatry. 2005;29(3): 443-453.

56. Startin CM, Hamburg S, Hithersay R, Davies A, Rodger E, Aggarwal N, Al-Janabi T, Strydom A. The LonDownS adult cognitive assessment to study cognitive abilities and decline in Down syndrome. Wellcome Open Research. 2016;1: 11.

57. Walker B, MacBryer S, Jones A, Law J. Interinformant agreement of the dementia questionnaire for people with learning disabilities. British Journal of Learning Disabilities. 2015;43(3): 227-233.

58. Hartley SL, Handen BL, Devenny DA, Hardison R, Mihaila I, Price JC, Christian BT. Cognitive functioning in relation to brain amyloid- $\beta$ in healthy adults with Down syndrome. Brain: A Journal of Neurology, 2014;137(Pt 9): 2556-2563.

59. Witts P, Elders S. The 'Severe Impairment Battery: Assessing cognitive ability in adults with Down syndrome. British Journal of Clinical Psychology, 1998;37(2): 213-216.

60. B0ada M, Alegret M, Buendia M, Hernández I, Viñas G, Espinosa A, et al. The usefulness of standard neuropsychological testing for adults with Down syndrome and dementia. International Medical Review on Down Syndrome. 2008;12(1):2-7.

61. Burt DB, Primeaux-Hart S, Loveland KA, Cleveland LA, Lewis KR, Lesser J, Pearson PL. Aging in Adults With Intellectual Disabilities. American Journal on Mental Retardation. 2005;110(4): 268-284. 
62. De Vreese LP, Mantesso U, De Bastiani E, Marangoni A, Gomiero T. Psychometric evaluation of the Italian version of the AADS questionnaire: A caregiver-rated tool for the assessment of behavioral deficits and excesses in persons with intellectual disabilities and dementia. International Psychogeriatrics. 2011;23(7): 1124-1132.

63. De Vreese LP, Gomiero T, Uberti M, De Bastiani E, Weger E, Mantesso U, Marangoni A. Functional abilities and cognitive decline in adult and aging intellectual disabilities Psychometric validation of an Italian version of the Alzheimer's Functional Assessment Tool (AFAST): Analysis of its clinical significance with linear statistics and artificial neural networks. Journal of Intellectual Disability Research. 2015;59(4): 370384.

64. Esteba-Castillo S, Dalmau-Bueno A, Ribas-Vidal N, Vilà-Alsina M, Novell-Alsina R, García-Alba J. Adaptation and validation of CAMDEX-DS (Cambridge Examination for Mental Disorders of Older People with Down's Syndrome and others with intellectual disabilities) in Spanish population with intellectual disabilities. Revista de neurología. 2013;57(8): 337.

65. Gomiero T, Bertelli M, Deb S, Weger E, Marangoni A, De Bastiani E, De Vreese LP. A Multicentre Italian Validation Study in Aging Adults with Down Syndrome and Other Forms of Intellectual Disabilities: Dementia Screening Questionnaire for Individuals with Intellectual Disabilities. Current Alzheimer Research. 2017;14(7).

66. Kirk LJ, Hick R, Laraway A. Assessing dementia in people with learning disabilities: The relationship between two screening measures. Journal of Intellectual Disabilities. 2006;10(4): 357-364.

67. Walsh DM, Doran E, Silverman W, Tournay A, Movsesyan N, Lott IT. Rapid assessment of cognitive function in down syndrome across intellectual level and dementia status. Journal of Intellectual Disability Research. 2015;59(11): 1071-1079.

68. Holland AJ, Ball SL. The Cambridge Examination for Mental Disorders of Older People with Down's Syndrome and Others with Intellectual Disabilities (CAMDEX-DS). In Neuropsychological assessments of dementia in Down syndrome and intellectual disabilities. London: Springer. 2009: 107-127.

69. Hon J, Huppert FA, Holland AJ, Watson P. Neuropsychological assessment of older adults with Down's syndrome: An epidemiological study using the Cambridge Cognitive Examination (CAMCOG). The British Journal of Clinical Psychology. 1999;38 (Pt 2): 155-165.

70. Huppert FA, Brayne C, Gill C, Paykel ES, Beardsall L. CAMCOG-A concise neuropsychological test to assist dementia diagnosis: Socio-demographic determinants in an elderly population sample. British Journal of Clinical Psychology. 1995; 34(4): 529-541.

71. Cosgrave MP, McCarron M, Anderson M, Tyrrell J, Gill M, Lawlor BA. Cognitive decline in Down syndrome: A validity/reliability study of the test for severe impairment. American Journal of Mental Retardation: AJMR. 1998;103(2): 193-197.

72. McCarron M, Gill M, Lawlor B, Beagly C. A pilot study of the reliability and validity of the Caregiver Activity Survey-Intellectual Disability (CAS-ID). Journal of Intellectual Disability Research: JIDR. 2002;46(Pt 8): 605-612.

73. Pyo G, Kripakaran K, Curtis K, Curtis R, Markwell S. A preliminary study of the validity of memory tests recommended by the Working Group for individuals with moderate to severe intellectual disability. Journal of Intellectual Disability Research: JIDR. 2007;51(Pt 5): 377-386.

74. Tyrer P, Tyrer F, Hanney M, Tyrer S. Measuring Outcomes Including Use of Rating Scales and Instruments in People with Intellectual Disability. Oxford Textbook of the Psychiatry of Intellectual Disability. 2020;43.

75. Das JP, Mishra RK. Assessment of cognitive decline associated with aging: A comparison of individuals with Down syndrome and other etiologies. Research in Developmental Disabilities. 1995;16(1): 11-25.

76. Das JP, Divis B, Alexander J, Parrila RK, Naglieri JA. Cognitive decline due to aging among persons with Down syndrome. Research in Developmental Disabilities. 1995;16(6): 461-478.

77. Palmer GA. Neuropsychological profiles of persons with mental retardation and dementia. Research in Developmental Disabilities. 2006;27(3): 299-308.

78. Numminen H, Service E, Ahonen T, Ruoppila I. Working memory and everyday cognition in adults with Down's syndrome. Journal of Intellectual Disability Research: JIDR. 2001;45(Pt2): 157-168.

79. Kalsy S, McQuillan S, Oliver C, Hall S, Oyebode J. The adults with Down's Syndrome Project: The Assessment of Adults with Developmental Disabilities (AADS) Questionnaire. Birmingham: University of Birmingham \& South Birmingham Primary Care NHS Trust. 2002. 
80. Makary AT, Testa R, Tonge BJ, Einfeld SL, Mohr C, Gray KM. Association between adaptive behaviour and age in adults with Down syndrome without dementia: Examining the range and severity of adaptive behaviour problems. Journal of Intellectual Disability Research: JIDR. 2015;59(8): 689-702.

81. Iacono T, Torr J, Wong HY. Relationships amongst age, language and related skills in adults with Down syndrome. Research in Developmental Disabilities. 2010;31(2): 568-576.

82. Prasher VP, Sachdeva N, Tarrant N. Diagnosing dementia in adults with Down's syndrome. Neurodegenerative disease management. 2015;5(3): 249-256.

83. Margallo-Lana ML, Moore PB, Kay DW, Perry RH, Reid BE, Berney TP, Tyrer SP. Fifteen-year follow-up of 92 hospitalized adults with Down's syndrome: incidence of cognitive decline, its relationship to age and neuropathology. Journal of Intellectual Disability Research. 2007 Jun;51(6):463-77.

84. Benejam B, Fortea J, Molina-López R, Videla S. Patterns of performance on the modified cued recall test in Spanish adults with down syndrome with and without dementia. American journal on intellectual and developmental disabilities. 2015 Nov;120(6):481-9.

85. Strydom A, Hassiotis A. Diagnostic instruments for dementia in older people with intellectual disability in clinical practice. Aging \& mental health. 2003 Nov 1;7(6):431-7.

86. Majerus S, Barisnikov K. Verbal short-term memory shows a specific association with receptive but not productive vocabulary measures in Down syndrome. Journal of Intellectual Disability Research. 2018 Jan;62(1):10-20.

87. Devinsky O, Sato S, Conwit RA, Schapiro MB. Relation of EEG alpha background to cognitive function, brain atrophy, and cerebral metabolism in Down's syndrome: Age-specific changes. Archives of Neurology. 1990 Jan 1;47(1):58-62.

88. Gutman M, Moskovic E, Jeret JS. Computerised cognitive testing of individuals with Down's syndrome and Alzheimer's disease. Journal of Intellectual Disability Research. 2016 Feb;60(2):179-81.

89. Crayton L, Oliver C, Holland A, Bradbury J, Hall S. The neuropsychological assessment of age related cognitive deficits in adults with Down's syndrome. Journal of Applied Research in Intellectual Disabilities. 1998 Sep;11(3):255-72.

90. Burt DB, Primeaux-Hart S, Phillips NB, Greene T, Loveland KA, Cummings E, Lewis KR, Lesser J, Cleveland L, Chen YR. Assessment of orientation: relationship between informant report and direct measures. Mental Retardation. 1999 Oct;37(5):364-70.

91. Devenny DA, Krinsky-McHale SJ, Sersen G, Silverman WP. Sequence of cognitive decline in dementia in adults with Down's syndrome. Journal of Intellectual Disability Research. 2000 Dec;44(6):654-65.

92. Beacher F, Simmons A, Daly E, Prasher V, Adams C, Margallo-Lana ML, Morris R, Lovestone S, Murphy $\mathrm{K}$, Murphy DG. Hippocampal myo-inositol and cognitive ability in adults with Down syndrome: an in vivo proton magnetic resonance spectroscopy study. Archives of general psychiatry. 2005 Dec 1;62(12):1360-5.

93. Kittler PM, Krinsky-McHale SJ, Devenny DA. Dual-task processing as a measure of executive function: a comparison between adults with Williams and Down syndromes. American Journal on Mental Retardation. 2008 Mar;113(2):117-32.

94. Pyo G, Ala T, Kyrouac GA, Verhulst SJ. A pilot study of a test for visual recognition memory in adults with moderate to severe intellectual disability. Research in developmental disabilities. 2010 Nov 1;31(6):1475-80.

95. Koran ME, Hohman TJ, Edwards CM, Vega JN, Pryweller JR, Slosky LE, Crockett G, de Rey LV, Meda SA, Dankner N, Avery SN. Differences in age-related effects on brain volume in Down syndrome as compared to Williams syndrome and typical development. Journal of neurodevelopmental disorders. 2014 Dec $1 ; 6(1): 8$.

96. Benejam B, Fortea J, Molina-López R, Videla S. Patterns of performance on the modified cued recall test in Spanish adults with down syndrome with and without dementia. American journal on intellectual and developmental disabilities. 2015 Nov;120(6):481-9.

97. Sinai A, Hassiotis A, Rantell K, Strydom A. Assessing specific cognitive deficits associated with dementia in older adults with Down syndrome: Use and validity of the Arizona Cognitive Test Battery (ACTB). PLoS One. 2016 May 12;11(5):e0153917.

98. Startin CM, Rodger E, Fodor-Wynne L, Hamburg S, Strydom A. Developing an informant questionnaire for cognitive abilities in Down syndrome: The Cognitive Scale for Down Syndrome (CS-DS). PLoS One. 2016 May 6;11(5):e0154596.

99. Lifshitz-Vahav H, Shnitzer S, Mashal N. Participation in recreation and cognitive activities as a predictor of cognitive performance of adults with/without Down syndrome. Aging \& Mental Health. 2016 Sep 1;20(9):955-64. 
100. Del Hoyo L, Xicota L, Langohr K, Sánchez-Benavides G, de Sola S, Cuenca-Royo A, Rodriguez J, RodríguezMorató J, Farré M, Dierssen M, de la Torre R. VNTR-DAT1 and COMTVal158Met genotypes modulate mental flexibility and adaptive behavior skills in Down syndrome. Frontiers in behavioral neuroscience. 2016 Oct 17;10:193.

101. de Knegt NC, Lobbezoo F, Schuengel C, Evenhuis HM, Scherder EJ. Pain and cognitive functioning in adults with Down syndrome. Pain Medicine. 2017 Jul 1;18(7):1264-77.

102. García-Alba J, Esteba-Castillo S, López MÁ, Hidalgo ER, Vidal NR, Díaz FM, Novell-Alsina R. Validation and Normalization of the Tower of London-Drexel University Test 2 nd Edition in an Adult Population with Intellectual Disability. The Spanish Journal of Psychology. 2017;20.

103. Gibson D, Groeneweg G, Jerry P, Harris A. Age and pattern of intellectual decline among Down Syndrome and other mentally retarded adults. International Journal of Rehabilitation Research. 1988.

104. Harper DC, Wadsworth JS. Dementia and depression in elders with mental retardation: A pilot study. Research in developmental disabilities. 1990 Jan 1;11(2):177-98.

105. Devenny DA, Hill AL, Patxot O, Silverman WP, Wisniewski KE. Ageing in higher functioning adults with Down's syndrome: An interim report in a longitudinal study. Journal of Intellectual Disability Research. 1992 Jun;36(3):241-50.

106. Devenny DA, Silverman WP, Hill AL, Jenkins E, Sersen EA, Wisniewski KE. Normal ageing in adults with Down's syndrome: A longitudinal study. Journal of Intellectual Disability Research. 1996 Jun;40(3):208-21.

107. Visser FE, Aldenkamp AP, Van Huffelen AC, Kuilman M. Prospective study of the prevalence of Alzheimer-type dementia in institutionalized individuals with Down syndrome. American Journal on Mental Retardation. 1997 Jan.

108. Krinsky-McHale SJ, Devenny DA, Silverman WP. Changes in explicit memory associated with early dementia in adults with Down's syndrome. Journal of Intellectual Disability Research. 2002 Mar;46(3):198208.

109. Devenny DA, Zimmerli EJ, Kittler P, Krinsky-McHale SJ. Cued recall in early-stage dementia in adults with Down's syndrome. Journal of Intellectual Disability Research. 2002 Sep;46(6):472-83.

110. Kittler P, Krinsky-McHale SJ, Devenny DA. Sex differences in performance over 7 years on the Wechsler Intelligence Scale for Children-Revised among adults with intellectual disability. Journal of Intellectual Disability Research. 2004 Feb;48(2):114-22.

111. Oliver C, Holland T, Hall S, Crayton L. Effects of increasing task load on memory impairment in adults with Down syndrome. American journal on mental retardation. 2005 Sep;110(5):339-45.

112. Krinsky-McHale SJ, Devenny DA, Kittler P, Silverman W. Selective attention deficits associated with mild cognitive impairment and early stage Alzheimer's disease in adults with Down syndrome. American Journal on Mental Retardation. 2008 Sep;113(5):369-86.

113. Makary AT, Testa R, Einfeld SL, Tonge BJ, Mohr C, Gray KM. The association between behavioural and emotional problems and age in adults with Down syndrome without dementia: Examining a wide spectrum of behavioural and emotional problems. Research in developmental disabilities. 2014 Aug 1;35(8):1868-77.

114. Carr J, Collins S. 50 years with Down syndrome: A longitudinal study. Journal of Applied Research in Intellectual Disabilities. 2018 Sep;31(5):743-50.

115. García-Alba J, Ramírez-Toraño F, Esteba-Castillo S, Bruña R, Moldenhauer F, Novell R, Romero-Medina V, Maestú F, Fernández A. Neuropsychological and neurophysiological characterization of mild cognitive impairment and Alzheimer's disease in Down syndrome. Neurobiology of aging. 2019 Dec 1;84:70-9. 